\title{
Yacimientos y estructuras del período Formativo en el Complejo Wari y entorno, Huamanga-Ayacucho
}

\section{Deposits and structures of Formative period in the Wari complex and surroundings, Huamanga-Ayacucho}

\author{
Ismael Pérez Calderón \\ https://orcid.org/0000-0003-2311-1590 \\ Universidad Nacional de San Cristóbal de Huamanga \\ zismaelunsch@hotmail.com
}

\section{RESUMEN}

Se presenta información sobre una variedad de cerámica atribuidas a ocupaciones tempranas o del período Formativo, en diversos yacimientos, la mayoría de los cuales reocupados en los períodos posteriores de los Desarrollos Regionales e Imperio Wari, dispersos en el área del espacio nuclear donde emergió la ciudad de Wari. Es por lo tanto una contribución para ampliar el conocimiento y profundizar el estudio sobre el origen, desarrollo, distribución espacial y funcionamiento de la metrópoli imperial.

Palabras clave: Yacimientos y estructuras; Formativo Inferior; espacio Wari.

\section{ABSTRAC}

Information is presented on a variety of ceramics attributed to early accupations or the Formative period, in variosus deposits, most of which reoccupied in the later periods of the Regional Developments and the Wari Empire, scattered in the área of de la Universidad Nacional Mayor de San Marcos. Este es un artículo de acceso abierto, distribuido bajo los términos de la licencia Creative Commons Atribución 4.0 Internacional (CC BY 4.0) [https: / / creativecommons. org/licenses/by/4.0/deed.es] que permite el uso, distribución y reproducción en cualquier medio, siempre que 
the cuclear sapace where the city emerged fron Wari. It is therefore a contribution to expand hnowledge an deepen the stady on the origin, development, sapatial distribution and operation of the imperial metropolis

Keyworks: Deposits an structures; Lower Formative; Wari space.

RECIBIDO: 10/10/2020 - ACEPTADO: 25/04/2021 - PubLICADO: 25/06/2021

\section{INTRODUCCIÓN}

El propósito fundamental del presente trabajo es dar a conocer la existencia de algunos sitios o lugares con restos de cultura material atribuidos al período Formativo, de manera especial a la fase Inferior (1750-1000 a. C) o período Cerámico Inicial, que dio origen a la formación de la civilización andina en Ayacucho, a partir de la observación directa en varios sectores, vinculados con el desarrollo de la ciudad de Wari, capital política administrativa del imperio de nombre homónimo que imperó en los Andes peruanos entre los VII-X d.C.

La información que alcanzamos obedece al desarrollo de una serie de labores de impacto directo e indirecto de diferentes obras de infraestructura social que se vienen ejecutando en las últimas tres décadas, incluyendo los trazos y mejoramiento de carreteras de Ayacucho a Huancavelica, Huanta y San Francisco, o valle del VRAEM, esta última que pasa por el centro de la ciudad de Wari, así como la antigua carreta Chacco-Quinua que pasa cerca de varios asentamientos, hoy amenazados por una serie de invasiones y obras de mejoramiento de caminos vecinales y saneamiento básico de los distintos centros poblados establecidos en el espacio cultural Wari, que tiene como base la microcuenca del río Viñaque o Vinaque como registrara el cronista español Pedro Cieza de León en el siglo XVI.

Parte de la información que se presenta es aquella que fue acumulada para la formulación del Plan de Manejo del Complejo Arqueológico Wari, a cargo del Dr. Luis G. Lumbreras, con apoyo del Gobierno regional de Ayacucho, hace ya más de 10 años, referencias que han sido parcialmente publicadas en el Boletín de Lima bajo el título de arqueología del espacio Wari (Pérez, 2013, 2014).

\section{ANTECEDENTES}

Han pasado nueve décadas, de la visita y reconocimiento científico del yacimiento arqueológico de Wari por el Dr. Julio C. Tello, quien sostenía que por su extensión, uso de piedra tallada, edificios subterráneos, estatuas, socavones, cuevas, arcillas y tierras de color para la alfarería y piedras para las construcciones, las ruinas de Wari, eran en ciertos aspectos superiores a las de Tiwanako y, en base a la presencia de cerámica procedente de los niveles inferiores de un basural en el cerro Tanta 
Orqo (sitio 10 del presente artículo), Tello citado por Medida (1931), atribuye que pertenecería a la primera época o cultura arcaica, de muchos siglos antes de la era cristiana. Tello retornó en 1942 para seguir explorando Wari, Conchopata y Acuchimay, de lo que contamos con amplia información sobre el monumento y del primer croquis del conjunto arqueológico (Tello, 2014).

Cuatro años después de la segunda intervención del Dr. Tello, los arqueólogos norteamericanos Rowe, Collier y Willey (1950), efectúan un breve reconocimiento solo en un solo sector de Wari (Capillapata), con recolección de cerámica y, en base a la decoración logran dividir en serie Huari, con las variantes de Huari Policromo N (con influencia Nasca); Huari Polícromo T (con influencia Tiahuanaco) y Huari Polícromo O (de siete colores sobre engobe anaranjado pulido); series Huarpa Negro sobre Blanco, Huamanguilla y Tanta Orqo, las dos primeras de la misma época y la última tardía. Como se puede deducir no llegaron a definir cerámica más antigua o temprana. Finalizando la década del cuarenta Bennett (1953), lleva a cabo excavaciones a pequeña escala en diferentes partes de Wari, levantando el primer plano con la técnica de triangulación en el que ubica las unidades de excavación, con relación a la cerámica los agrupa en series Wari y Huarpa, además de estilos Ayacucho y Acuchimay, cada una con sus respectivas subdivisiones. En esta ocasión tampoco se da referencia alguna sobre cerámica más antigua. En 1957 Lumbreras (1960), analiza parte del material cerámico recolectado por Tello en 1942, quien basado en los atributos de composición de la pasta, manufactura, morfología y decoración divide en el complejo estilístico Wari-Ayacucho con los estilos del mismo nombre, el primero con las subdivisiones de Huamanguilla o Wari Bicromo, Conchopata y Wari polícromo y el segundo llamado Ayacucho polícromo de Bannett y Wari N de Rowe, Collier y Willey; estilos Okros, Wari Cursivo, cerámica con decoración incisa, estilo Marañón (Cajamarca), estilos Negro Decorado, Negro sobre Blanco o Huarpa, entre otros, ninguno de estos de épocas precedentes a Huarpa, como base para la secuencia maestra del Horizonte Medio propuesta por Menzel (1964 y 1968), con los estilos Ocros, Conchopapa, Robles Moqo, Chaquipampa, Negro Decorado, Viñaque, etc., asociados a diferentes monumentos con ocupación Wari en los Andes peruanos.

José Casafranca, en su condición de inspector de monumentos en la Sierra Central del Perú, no solo supervisó las excavaciones de Bennett en Wari, sino también registró varios sitios con cerámica de estilo chavinoide, entre estos están los sitios de Alccomachay, Naupallacta, Tantawasi, Aicas, Huanchac Chico, Huanchac Grande, Atoc Puquio, Azangaro, Tucocc Orqo Ccala Orqo y Pampachacra en los alrededores de Huanta y Kichkapata, Osno Era y 0sno Pampa, en Chupas en la parte alta de la provincia de Huamanga. En los fragmentos de cerámica que ilustran el trabajo de Casafranca (1960), se puede ver no solo rasgos chavinoides sino también otras características propias a la cerámica inicial o prechavin. En esta misma época Flores (1960) y Vescelius (1974) trabajan Wichqana, que al igual que Usno Era en Chupas, 
fue excavado por Lumbreras $(1969,1974,1981)$, en el marco del proyecto Prehistoria de la cuenca de Ayacucho, Perú dirigido por MacNeish, donde encuentra una superposición de estructuras con cerámica de las fases Andamarca, Wichqana y Chupas, atribuidas al Formativo inferior, medio y superior respectivamente.

A raíz de las excavaciones desarrolladas en el sector de Cheqowasi, Benavides (1983) señala haber encontrado indicios de una ocupación anterior a la sociedad Warpa, representado por los estilos Kichkapata y Wichqana comparables con los estilos Pukara y Kallamarca del Altiplano peruano boliviano y menciona que los estratos de las excavaciones de William Isbell en el cerro Churucana, contenían estructuras tempranas de barro (adobes). Al respecto, en el año 1974, Isbell (1991, 2001) excava la cima del cerro Churucana como parte del proyecto prehistoria urbana de Wari, donde efectivamente encuentra estructuras de adobe en los estratos más profundos, asociados con cerámica de estilo Wichaqana, a la que denomina fase Churucana (1000-200 a. C), planteamiento que como veremos más adelante han sido corroborados con nuevos trabajos efectuados bajo la dirección de Yuri Cavero.

En el sector de Barrios Altos de la ciudad de Ayacucho, Ochatoma (1985a), como resultado de labores de rescate en una vivienda, logra definir un conjunto de entierros en el interior de modestas habitaciones circulares (una de aparente forma en "D"), asociadas con cerámica de estilo local temprano (Qarqampata), Wichaqana y otros fragmentos vinculados con la influencia Chavín (Chupas) y Paracas, del Período Formativo conocido como Horizonte Temprano, indicadores de una probable relación cultural con otros regiones. En los dibujos de cerámica que ilustran el informe presentado para el curso de Seminario III en la UNSCH, se aprecia algunos fragmentos incisos de ollas sin cuello, propios del Formativo Inferior o Cerámico Inicial, como bien lo define en el cuadro comparativo sobre las secuencias cronológicas establecidas para Ayacucho (Ochatoma, 1985b). De este mismo lugar se recuperó un conjunto de vasijas de clara influencia Cupisnique de la costa norte del Perú (Ochatoma, Pariahuamán y Larrea, 1984), (Ochatoma, 1985b, 1992,1998). Continuando con los trabajos en las cercanías de la ciudad de Ayacucho, Raúl Mancilla Mantilla, efectúa excavaciones en el sitio Ira Qata, en la margen derecha de la quebrada del mismo nombre que drena a la quebrada Pilacucho a menos de $1 \mathrm{k}$ en línea recta al sur de Jarqam Pata, y hace mención del hallazgo de cerámica de los estilos Wichqana, Kichakapata, Chupas, Rancha y Qarqampata, atribuidos de manera general al período Formativo, pero según los dibujos de cerámica que ilustra el tesis (Mancilla 2008), los fragmentos encajan a la clasificación del Formativo Inferior (estilo Qarqampata y Wichqana), Formativo Medio (estilos Kichkapata y Chupas) y Formativo superior (estilo Rancha).

En lo que va las dos primeras décadas del presente milenio, el panorama sobre el Formativo en Ayacucho se ha fortalecido con nuevas evidencias definidas por 
Matzumoto y Cavero (2009), en Campanayoq Rumi-Vilcashuaman, donde han expuesto los restos de un templo ceremonial con patio cuadrangular hundido al que se accede por graderías desde las plataformas superiores, asociado a cerámica del período Formativo Inferior-Medio (Campanayoc I y II), de rasgos locales y foráneas a la región de Ayacucho, producto del contacto interregional con poblaciones de la costa, sierra y selva andina: Por su parte, Mendoza (2017) que ha llevado a efectuado excavaciones en Pallaucha-Vilcashuaman, ha encontrado restos de estructuras superpuestas asociadas a cerámica del período Formativo Medio-Tardío, destacando algunos fragmentos que señalan cierta influencia de Paracas; Pérez y Paredes (2016), Pérez y Quispe (2019), que han trabajado en el sitio de Waychaupampa-Huamanga, han definido un conjunto de estructuras con cerámica atribuida a las distintas fases del periodo Formativo, destacando algunos fragmentos que indican una cierta influencia con la región de la selva. A inicios de la segunda década del presente milenio, Huamaní (2014), Cavero y Huamaní (2015), hacen referencia de Churucana, parte alta del Complejo Wari, donde a consecuencia de labores de monitoreo arqueológico para la instalación de agua potable a las poblaciones aledañas establecidas en el Complejo Wari, han registrado restos de una probable estructura ceremonial asociada con cerámica del período Formativo Medio (Horizonte Temprano), reocupado posteriormente en las épocas Huarpa y Huari.

En los últimos años, Edison Mendoza y Cirilo Vivanco (2015) vienen explorando la zona de Pomabamba en Cangallo, con excavaciones en el yacimiento de Apu Urqu, en Tukri, donde han dado a conocer la presencia de una estructura ceremonial de carácter monumental, constituida por plataformas dispuestas en forma de "U", y con cerámica que denota una clara influencia Chavín, comparativamente semejante a los sitios de Atalla en Huancavelica, Paullaucha y Campanayuq en Vilcashuaman, Ayacucho, atribuido al período Formativo Medio de la secuencia planteada por Lumbreras (1969) y al Horizonte Temprano, según Rowe (1958).

\section{METODOLOGÍA Y TÉCNICAS}

La localización y registro de datos se realizó en diferentes fechas aprovechando el desarrollo de labores de monitoreo ejecutadas de diversas obras de infraestructura social y económica, tales como mantenimiento y acondicionamientos de carreteras y caminos vecinales, inspecciones de superficie para la obtención de CIRA, observación de espacios con obras nuevas y preexistentes, para el mejoramiento del servicio de agua potable y alcantarillado, con fuentes de agua traídas desde las nacientes, instalación de unidades básicas de saneamiento, etc. Logrando registrar una seré de evidencias, como las que existen en las áreas que ocupan los actuales cementerios del centro poblado de la Compañía y San Juan de la Viñaca (sitios 14 y 16 del presente trabajo), al igual que la carretera que pasa cerca de los asentamientos de Churucana en la parte alta del Complejo Wari (sitio 6), cerro Churo (sitio 8) y Chichkaorqo 
(sitio 14), etc. También algunos centros poblados se han levantado sobre vestigios culturales de culturas preincaicas, caso de Vista Alegre (sitio 24), Pampachacra (23), incluyendo el mismo pueblo de Pacaycasa, donde se tiene e registrado los sitios de Quiwicho/Quihuiucho, y Tanta Orqo (sitios 9,10), etc. (figura 01).

La delimitación del núcleo urbano o área monumental de Wari, es aproximada en base a fotos satelital de Google Earth, mientras que la delimitación del área intangible de todo el complejo, es trasponiendo los puntos que delimitan la propuesta del plano de delimitación hecho en 1996 por la Universidad Nacional de San Cristóbal de Huamanga en Convenio con el Gobierno regional "Los libertadores Wari" (Hoy Gobierno Regional Ayacucho), digitalizada posteriormente por la Dirección Regional de Cultura de Ayacucho (actual DDC-A), con apoyo de FONCODES, útil para trabajos de investigación, protección y puesta en valor. El mapa que se adjunta ha sido elaborado en el sistema argis 10.3 con datos cartográficos de la zona de trabajo, en este caso se tomó como fuente la carta 27ñ, adquirida del Instituto Geológico Minero y Metalúrgico (INGEMMET), de la cual solo utilizamos la formación de los ríos y curvas de nivel, como referentes para ubicar los puntos tomados en campo y delimitar las zonas de interés (área monumental y área intangible). La creación del mapa satelital, es con imagen de alta resolución que brinda el mismo programa, el otro mapa de curvas de nivel, es con los datos extraídos de la carta nacional 27ñ, advirtiéndose la vulnerabilidad del Complejo Arqueológico de Wari, ante el crecimiento incontrolado de poblados asentados en el interior del área intangible, así como de la mayoría de sitos registrados sujetos a invasiones o lotizaciones de particulares (traficantes de terrenos), (figuras 01 y 02).

\section{RESULTADOS}

Siguiendo a Renfrew y Bahn (2007), utilizamos los términos yacimiento para los sitios o asentamientos con arquitectura, cerámica y otros elementos culturales visibles a nivel de superficie del terreno, y estructura a los lugares con cerámica u otro material cultural no arquitectónico disperso en la superficie.

\section{Vegachayoqmoqo}

Sector de Wari, que ocupa la parte baja de la ciudad (596786.8728E/8556153.0633N), a $2723 \mathrm{~m} \mathrm{s.} \mathrm{n.} \mathrm{m.,} \mathrm{la} \mathrm{información} \mathrm{que} \mathrm{alcanzamos} \mathrm{se} \mathrm{debe} \mathrm{a} \mathrm{las} \mathrm{referencias} \mathrm{alcanza-}$ das en algunos fragmentos de cerámica del trabajo presentado por González, et, al. (1995), como resultado del análisis de la cerámica recupera de los trabajos de limpieza y excavación para la restauración y conservación del monumento (frontis o lado oeste del montículo), de aparente forma troncopiramidal, que fuera intervenido a inicios de la década de los ochenta del segundo milenio, por Bragayrac y González (1982). Los fragmentos de cerámica aludidos corresponden a ollas sin cuellos de va- 


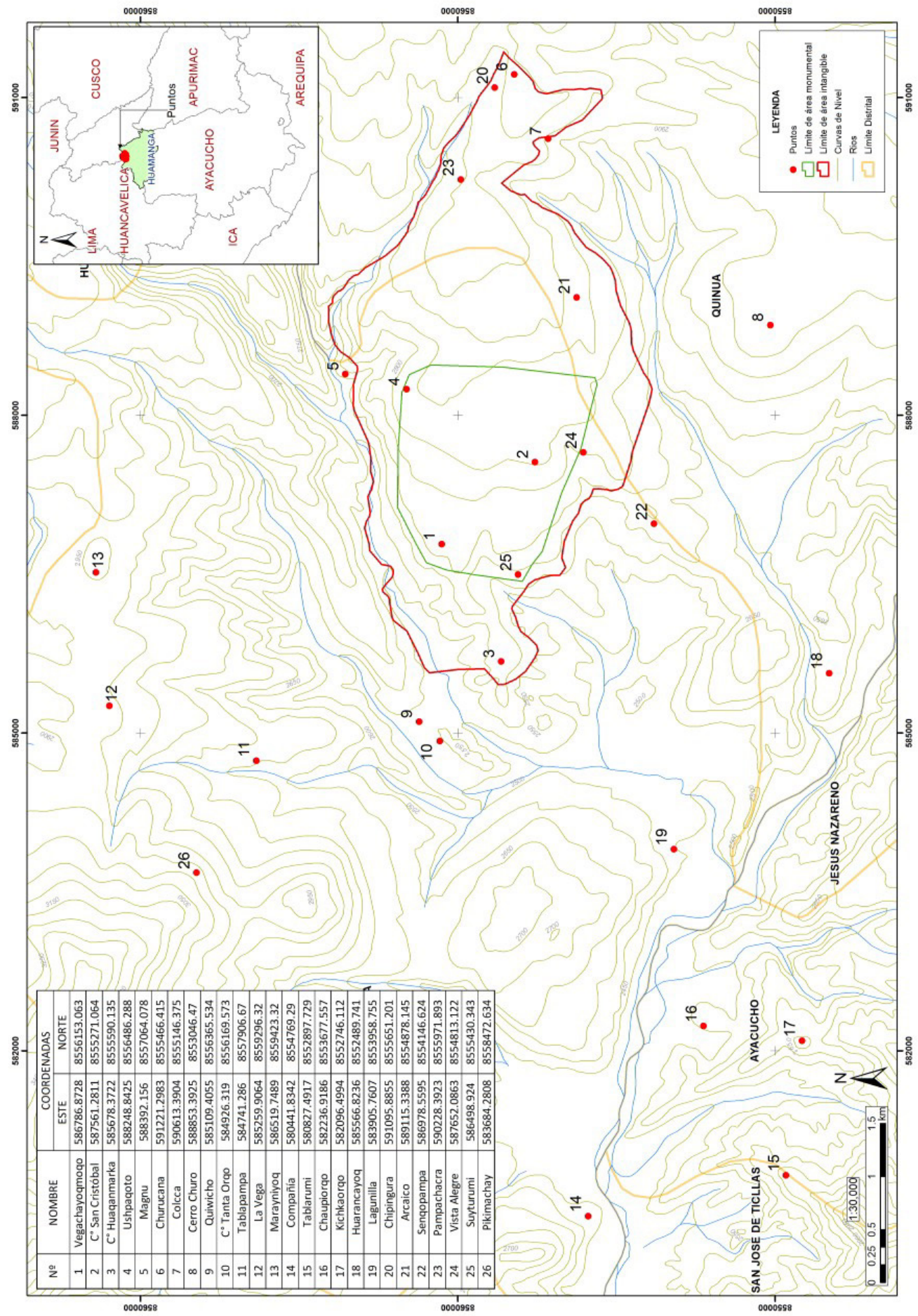

Figura. 01. Mapa con la distribución espacial de asentamientos del período Formativo en el complejo arqueológico Wari y alrededores 


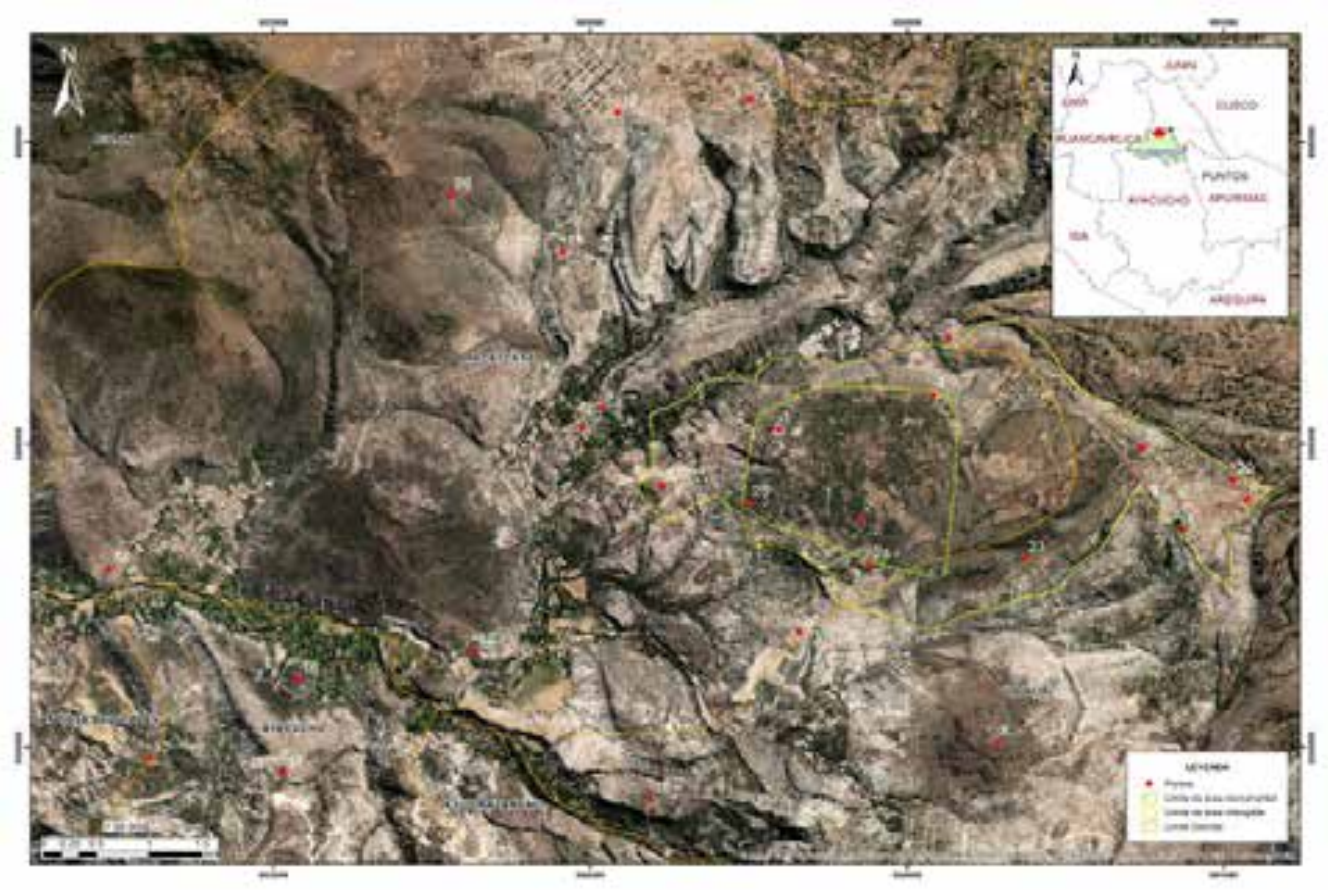

Figura 02. Ubicación de yacimientos y estructuras del período Formativo en foto satelital del complejo arqueológico Wari y entorno inmediato

sijas del periodo Cerámico Inicial o Formativo Inferior. Por otro lado, si observamos la muralla oeste, se ve que corta el lado norte de la estructura escalonada, la cual es evidentemente más antigua.

\section{Cerro San Cristóbal}

Dispuesto a manera de cortina natural en la parte alta del lado este del área urbana o monumental (587561.2811E/8555271.064), a 2817 m s. n. m., se caracteriza con presentar tres cuevas: Machaypampa, Infiernillo e Intipunku, las dos últimas sirvieron de canteras para la extracción de arcilla. La cima es plana, en cuya superficie existe abundante fragmentaría de cerámica dentro de los que se puede percibir algunos del periodo Formativo Inferior, consistentes en bordes de ollas sin cuello y bordes impresos y dentados, asociados a cabeceras circulares de estructuras próximas al borde de la cantera de piedra conocido como "canterón". El cerro fue explorado por el Dr. Tello en 1942, quien registró la cueva del Infiernillo y la tumba subterránea que existe en la cima.

\section{Cerro Huaqanmarca}

Prominente elevación, con laderas empinadas erosionadas por el tiempo, se ubica en el extremo oeste del área intangible, separado del área monumental Wari 
(585678.3722E/8555590.135N), 2647 m s. n. m., accesible sólo por el lado norte; la cima es plana y mide aproximadamente $180 \mathrm{~m}$ de largo por $120 \mathrm{~m}$ de ancho, presenta abundante material cultural de superficie como cerámica de las épocas Formativa, Huarpa, Wari y Chanka asociados a restos de arquitectura de diferentes ambientes. Este cerro, visto desde la parte baja, tiene la forma de un baúl (figura 03), semejante al cerro Baúl de Moquegua, que actualmente representa la máxima expansión Wari en el sur del Perú. Fue excavado por Vaquerizo (2013), quien confirma la ocupación temprana con cerámica y arquitectura.

\section{Ushpaqoto}

Montículo localizado en el exterior de la muralla que encierra al sector o barrio de Ushpaqoto (588248.84254E/8556486.288N), 2840 m s. n. m., al NE de la zona urbana de Wari. Se caracteriza por presentar una morfología en forma "U" con el lado abierto hacia el noreste (figura 04). La superficie contiene cerámica Huarpa y Wari, pero también algunos fragmentos del período Formativo, en bordes de ollas sin cuello con incisiones y aplicaciones, dispersos cerca del filo del barranco.

\section{Magnu (2 $600 \mathrm{~m} \mathrm{s.n.m.)}$}

Promontorio ubicado entre la confluencia de las quebradas Llamahuillcca, Chipingura y Putica (588392.156E/8557064.078N), 2713 m s. n. m., presenta laderas escarpadas y empinadas con acceso por las lados sur y norte, las laderas contienen líticos y cerámica arrasados por la fuerte erosión de la parte superior donde, presenta diferentes niveles de terrazas con cimentaciones de viviendas que llegan hasta la cima del promontorio (figura 05), hay espacios abiertos con abundante fragmentos de cerámica de los períodos Formativo, Huarpa, Wari y Chanka (Arqalla), destaca un tipo de cerámica de pasta roja sobre la que va decoración con pintura negra, al parecer es de producción local (figura 06). El lado sur que se encuentra encerrado por una muralla lo que convierte en un lugar fortificado.

\section{Churucana}

Colina ubicada en el extremo este del área intangible Wari, por donde va la carretera hacia Acos Vinchos (591221.2983E/8555466.415N), en la superficie del sitio no se observa estructura arquitectónica alguna, pero si abunda el material cerámico disperso en medio de chacras de cultivo en una extensión aproximada de 6 Has (figura 07), hay cerámica del Formativo, Huarpa, Wari, Cajamarca y Chanka. Churucana fue excavado por Isbell (2001), quien da referencias de arquitectura temprana a base de adobes, definida en pozos de cateo, también aparece mencionado por Benavides (1984) y confirmado por Cavero y Huamaní (2015), quienes dan a conocer la existencia de arquitectura superpuesta que se inicia en el del Horizonte Temprano, reocupado posteriormente en la épocas Huarpa y Wari (figura 08). 


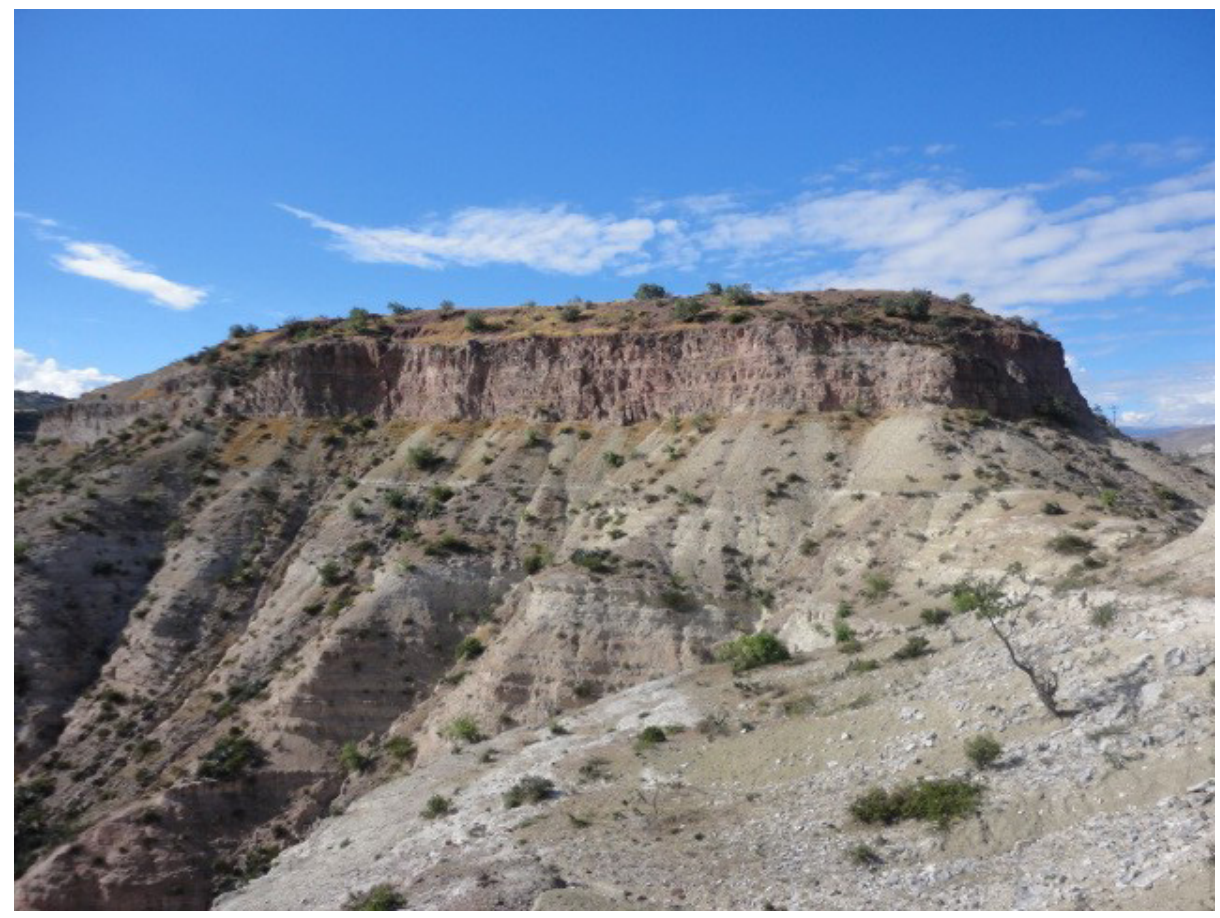

Figura 03. Panorámica del poblado fortificado de Huaqanmarca

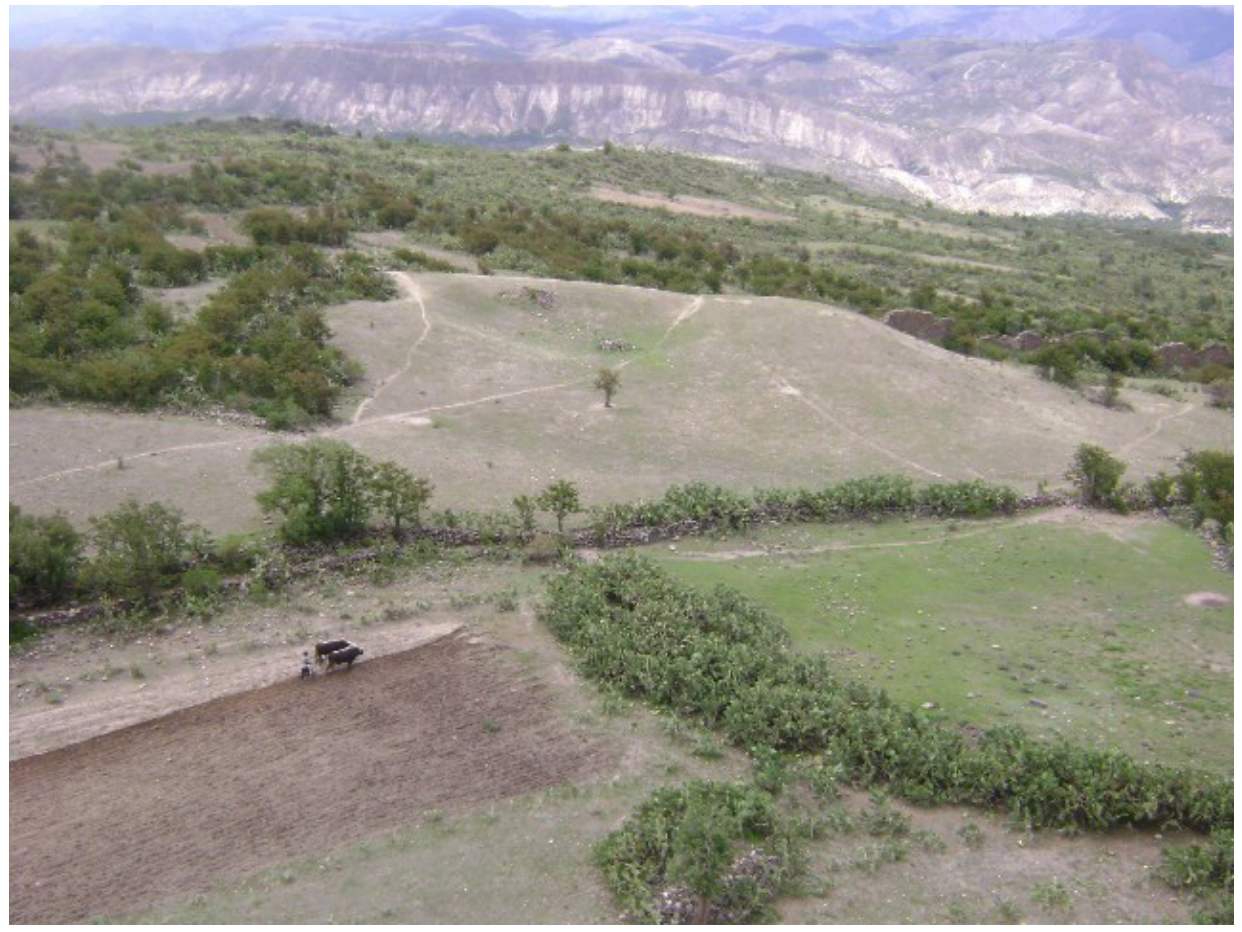

Figura 04. Montículo de Ushpaqoto en la parte alta de la zona urbana de Wari. 


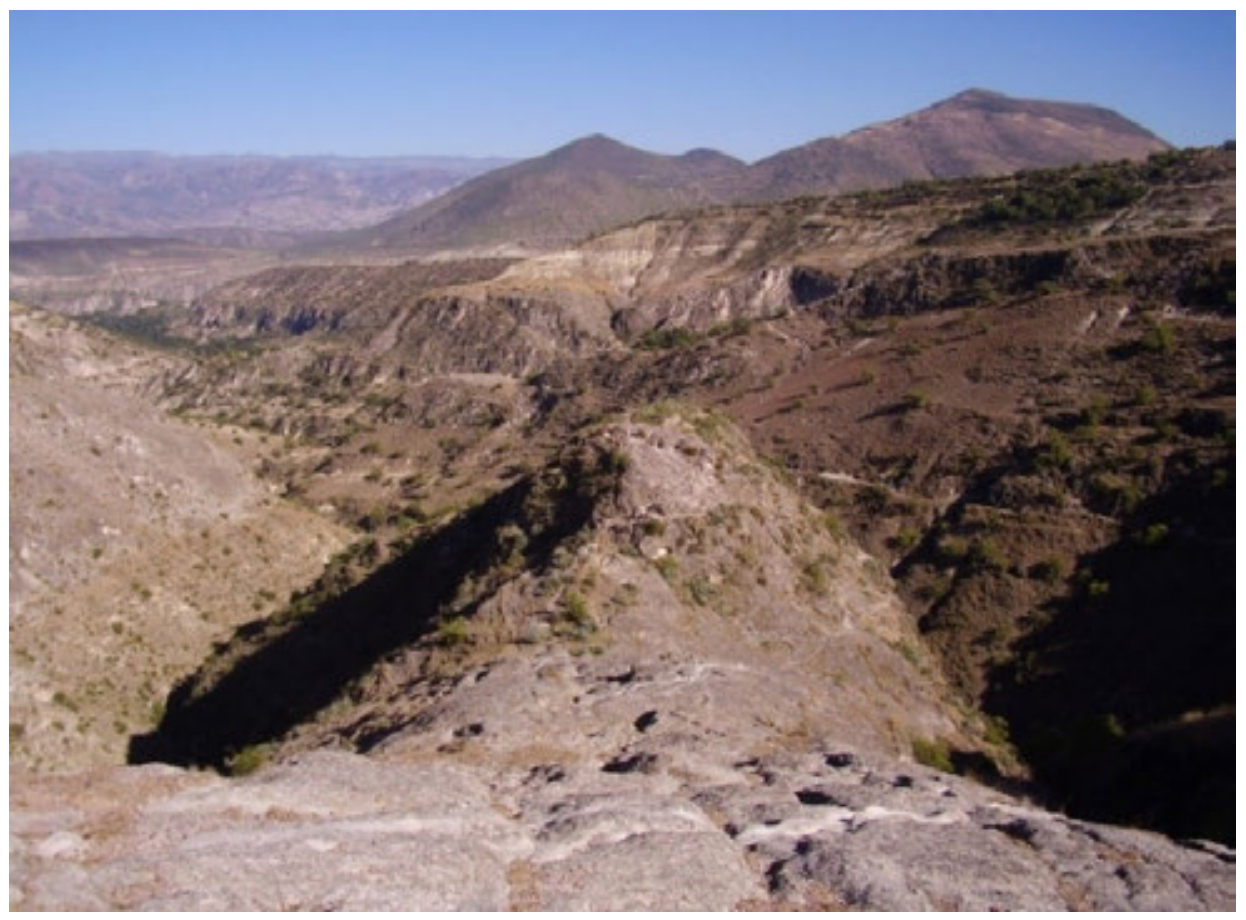

Figura 05. Promontorio de Magnu visto desde el lado sur
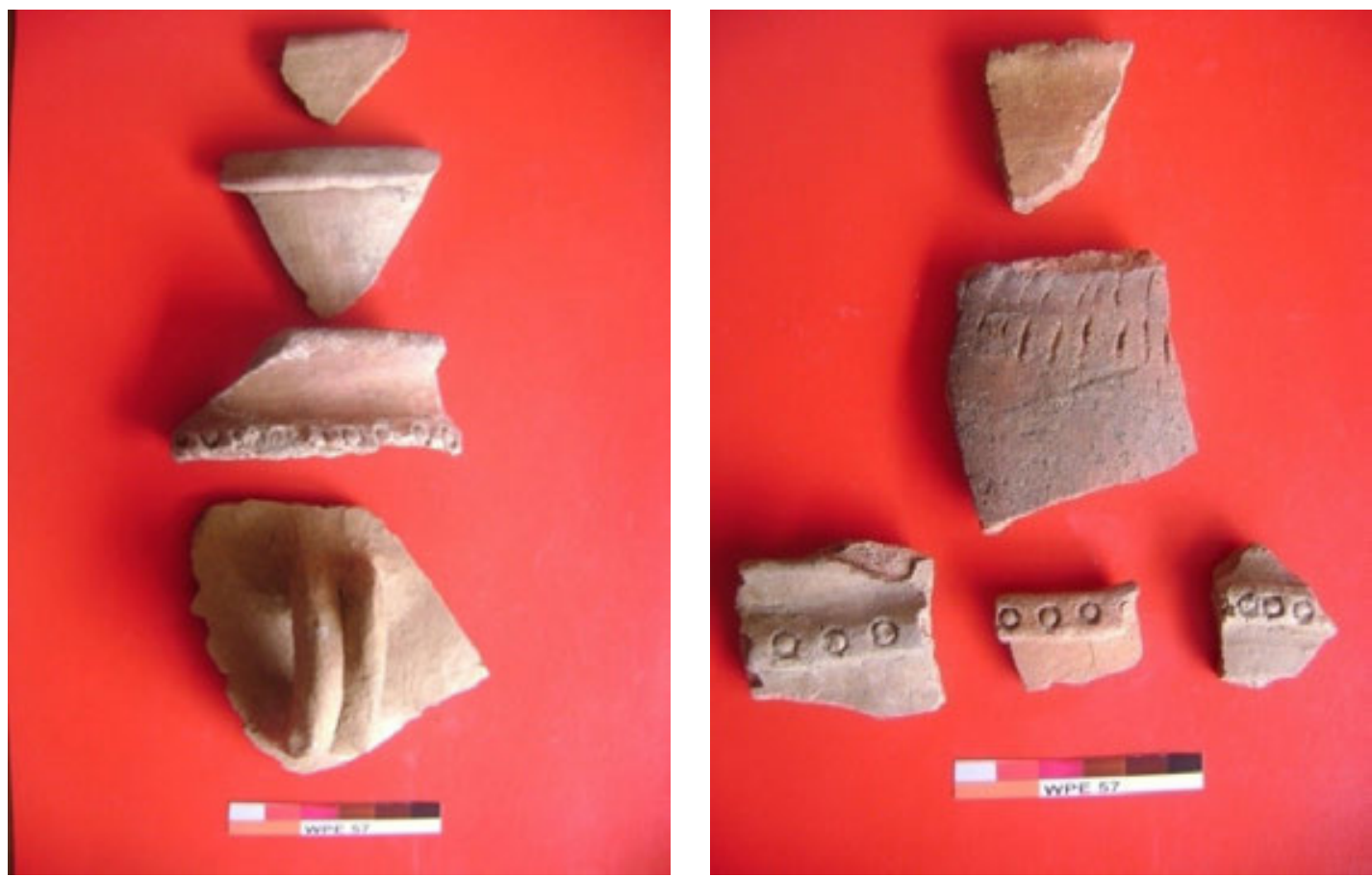

Figura 06. Cerámica del Formativo Medio y superior 


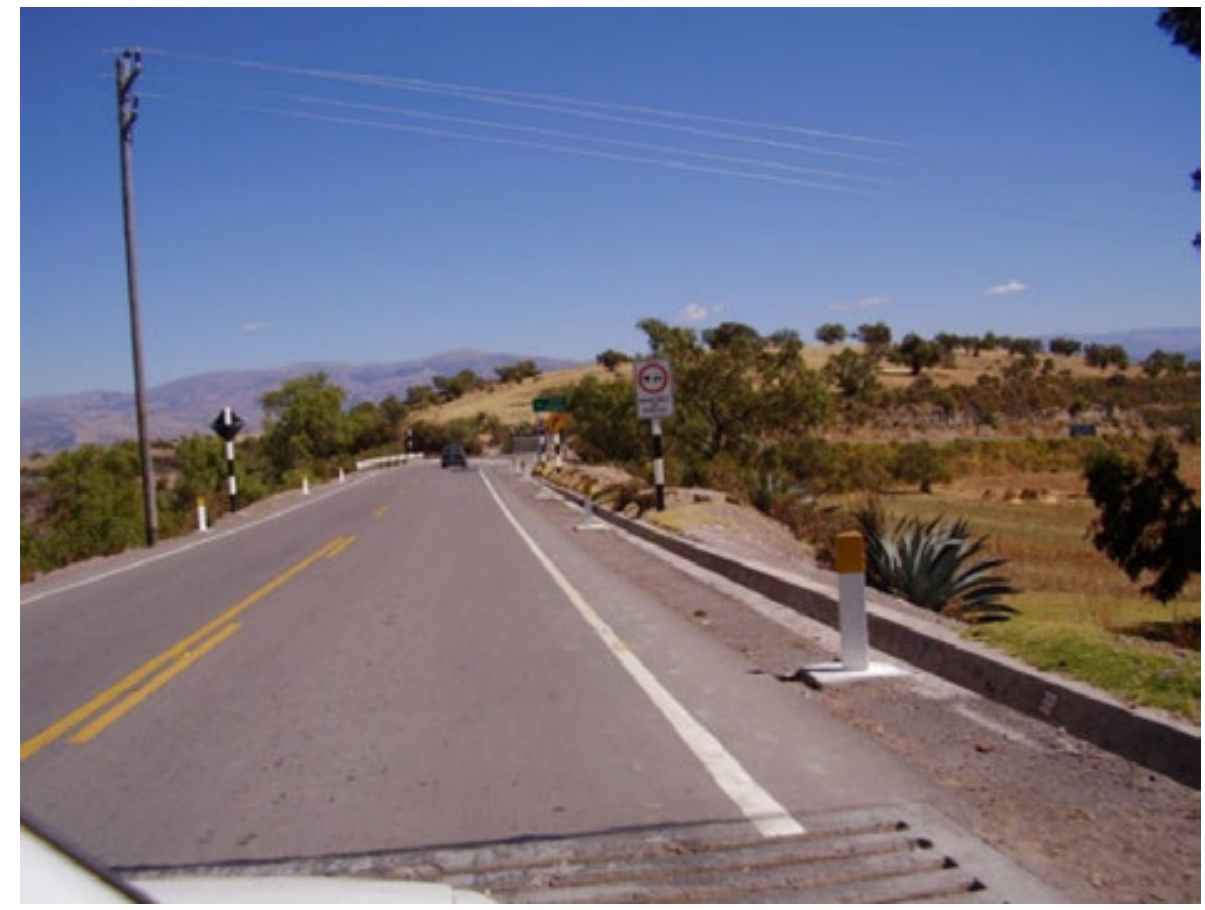

Figura 07. Carretera que va a Quinua al fondo $C^{\circ}$ Churucana
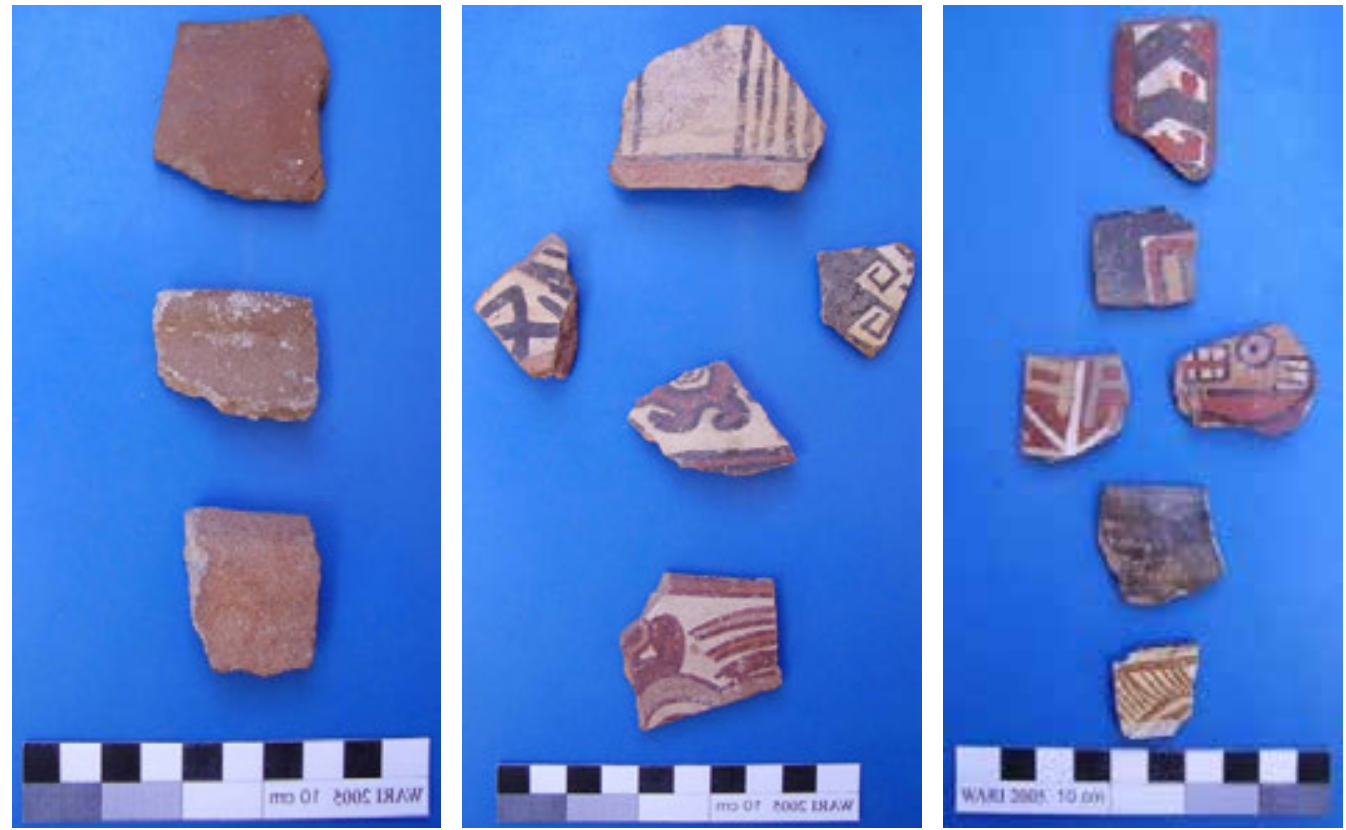

Figura 08. Cerámica procedente del cerro Churucana: a) Formativo;b) Huarpa Negro sobre Blanco y Tricolor; c) Chaquipampa, Viñaque, Negro decorado y Cajamarca. 


\section{Collcca}

Promontorio que dista $500 \mathrm{~m}$ al SE del Centro Educativo Inicial de Pampachacra (590613.3904E/8555146.375N), 2972 m s. n. m. Contiene cerámica de los períodos Formativo (inferior), Huarpa y Wari, dispersa en chacras de cultivo en el terreno de la familia Berrocal.

\section{Churo}

Se encuentra a $2 \mathrm{~km}$ en línea recta al sur del área monumental Wari, es una colina de forma troncónica conectada hacia el lado sur a una extensa planicie mientras que en los lados norte, este y oeste rodeado por laderas rocosas y empinadas de difícil acceso que descienden hasta la quebrada Checclla Huayqo y al centro poblado de Mituqasa (en la Carta Nacional 27ñ aparece con el nombre de Atumpampa), distrito de Quinua, Huamanga (588853.3925E/8553046.47), 2826 m s. n. m. (figura 09).

La cima del cerro es plana con abundante piedra pómez, geológicamente corresponde al cráter de un antiguo volcán, en cuyo espacio resalta una estructura de patrón ortogonal en forma de "L" de $280 \mathrm{~m}$ de largo por 180m de ancho, delimitada por una muralla perimétrica y compuesta por una plaza que ocupa casi la mitad del espacio total (figura 10), abierta hacia el lado norte, y con grandes recintos

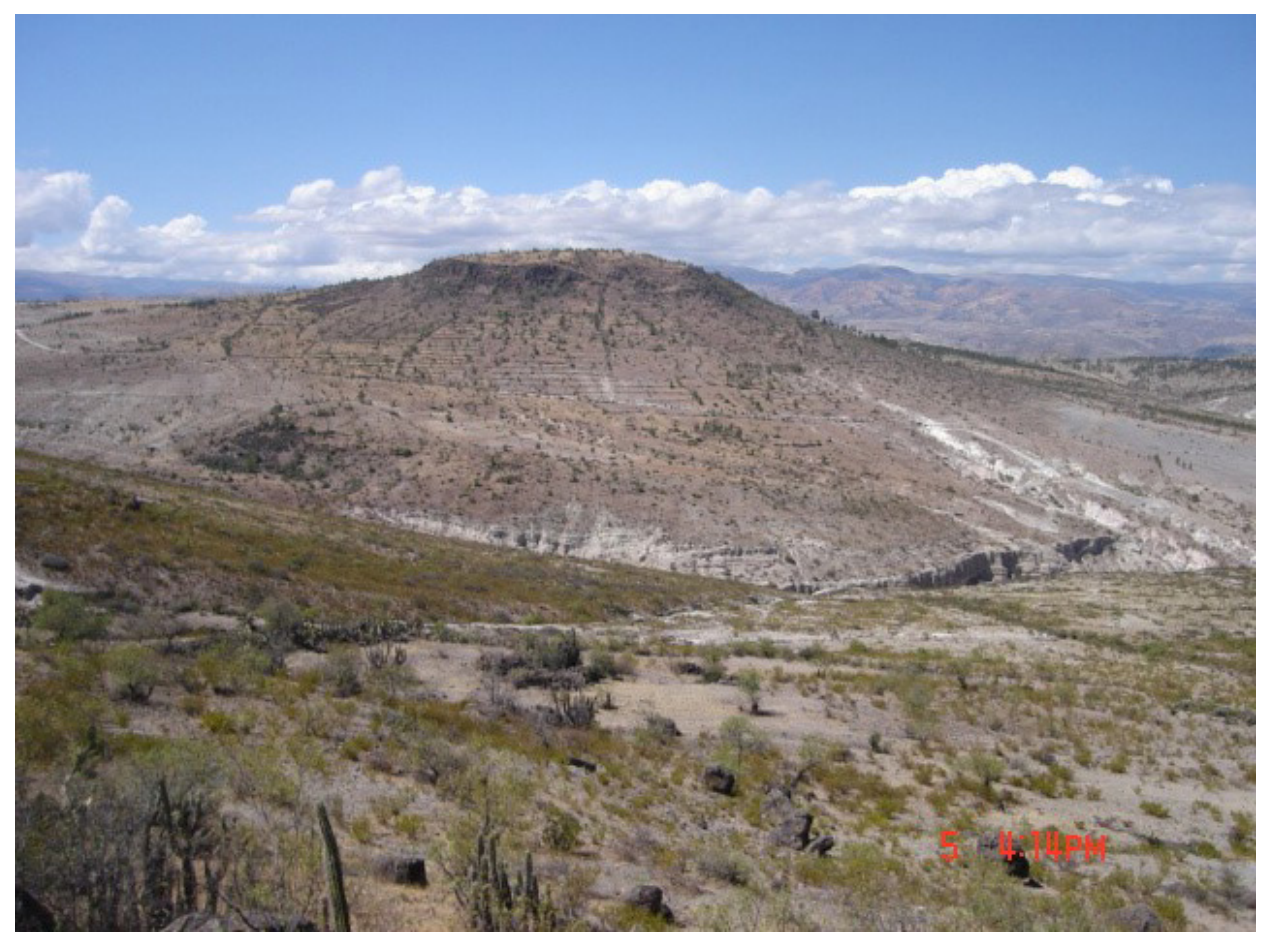

Figura 09. Cerro Churo/Atumpampa, visto desde Vista Alegre 
cuadrangulares en sus lados sur, este y oeste asociados con cerámica básicamente Huarpa y Wari, también fragmentos del período Formativo (figura 11) y artefactos de obsidiana, crisocola y cuarzo. Destacan algunos recintos circulares dispuestos cerca al ángulo NO de la plaza y otros en el ángulo NE exterior de la estructura cercada, asociados a cerámica de filiación local tardía. La configuración arquitectónica del cerro Churo denuncia haber sido construido en una sola etapa, probablemente corresponda a la de mayor expansión territorial Wari, formalmente es semejante a los sitios de Ichubamba y Yamobamba en la sierra norte y al sector de Patipampa en el Complejo Wari (Isbell, Pérez y Wolff, 2017).

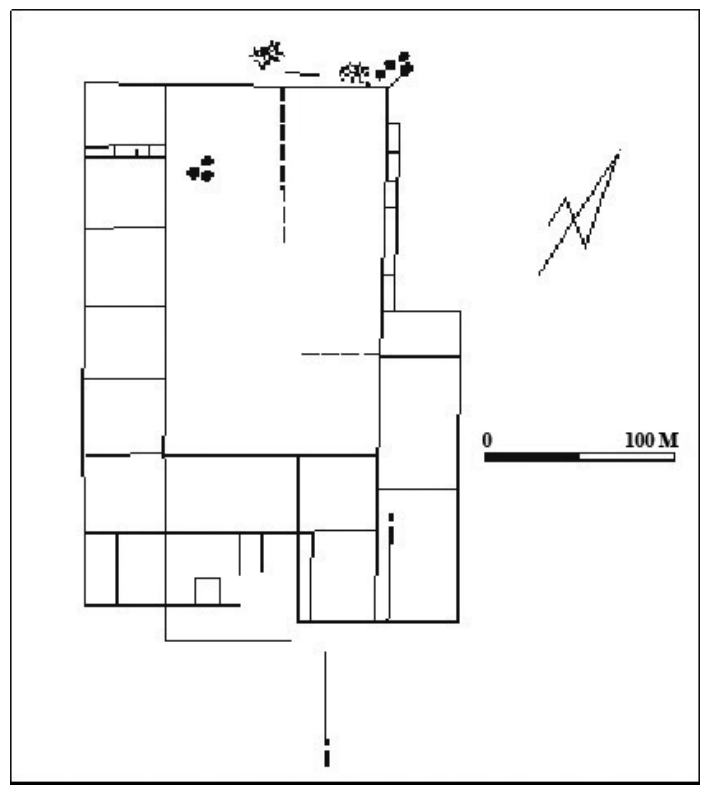

Figura 10. Arquitectura ortogonal del cerro Churo

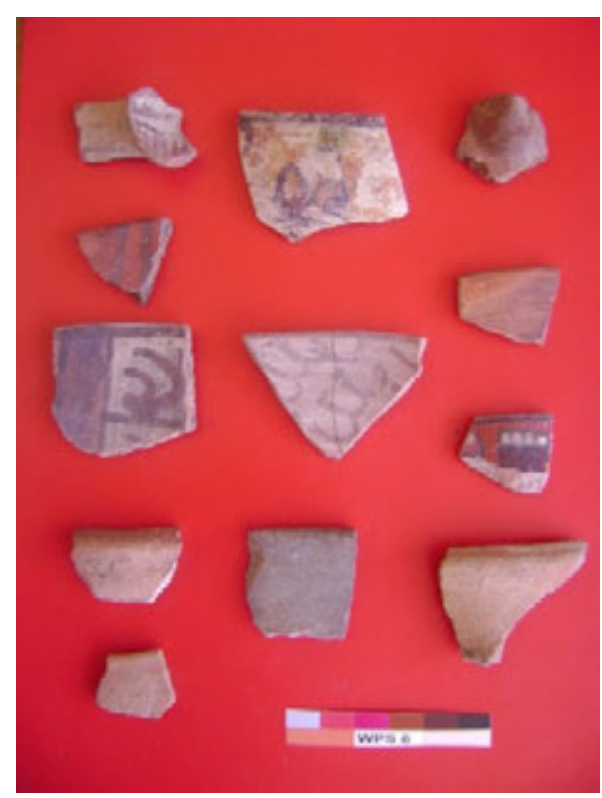

Figura 11.Cerámica del período Formativo, Huarpa y Wari

\section{Quiwiucho}

Perfil de terreno localizado en la ladera noroeste del cerro Chupapata, cerca de una pequeña capilla (585109.4045E/8556365.5336N), a la que se llega por una de las calles aproximadamente a $400 \mathrm{~m}$ de la plaza del pueblo de Pacaycasa. Parece corresponder a un montículo cortado por la proyección de la calle y viviendas del barrio Quihuiucho/Quiwiucho, el perfil presenta una borrosa estratificación con fragmentos de cerámica de los períodos Formativo, Desarrollos Regionales e Imperio Wari, dispuestos indistintamente haciendo notar que se trata quizá de material derrumbe de la cima del cerro adyacente (figura 12). 


\section{Tanta Orqo (2550 m s. n. m.)}

Poblado Wari establecido sobre la cima del cerro Tanta Orqo, entre Orcasitas y Pacaycasa, margen derecho de la quebrada Ocopa (8556400N, 584900E), 2540 m s. n. m., tiene una extensión aproximada de 8 Has. Como para albergar no menor de 3000 habitantes dividida en sectores con viviendas de patrón circular, cuadrangular y rectangular con amplios espacios abiertos, áreas de circulación, restos de terrazas y amurallamientos en el borde de la cima que lo hace inaccesible aparte de las altas peñas que rodean (figura12), se trata de una fortificación. En la superficie del yacimiento existe abundante cerámica que pertenecen a las distintas épocas culturas desde el Período Formativo hasta la época Chanca. El sitio fue explorado por el Dr. Julio C. Tello (1970), luego por Lumbreras (1974) y referido por Vivanco et, al (2000).

\section{Tablapampa}

Estructura ortogonal, ubicada en la falda de la pendiente que desciende del cerro Molinuyoq donde se localiza la cueva de Pikimachay, cruzando la quebrada Pacayhuayqo, al NE del pueblo de Pacaycasa (584741.2860E/8557906.6704N), $2725 \mathrm{~m} \mathrm{~s}$. n. m., el área cultural del sitio abarca entre 10 a 15 Has, Se caracteriza por presen-

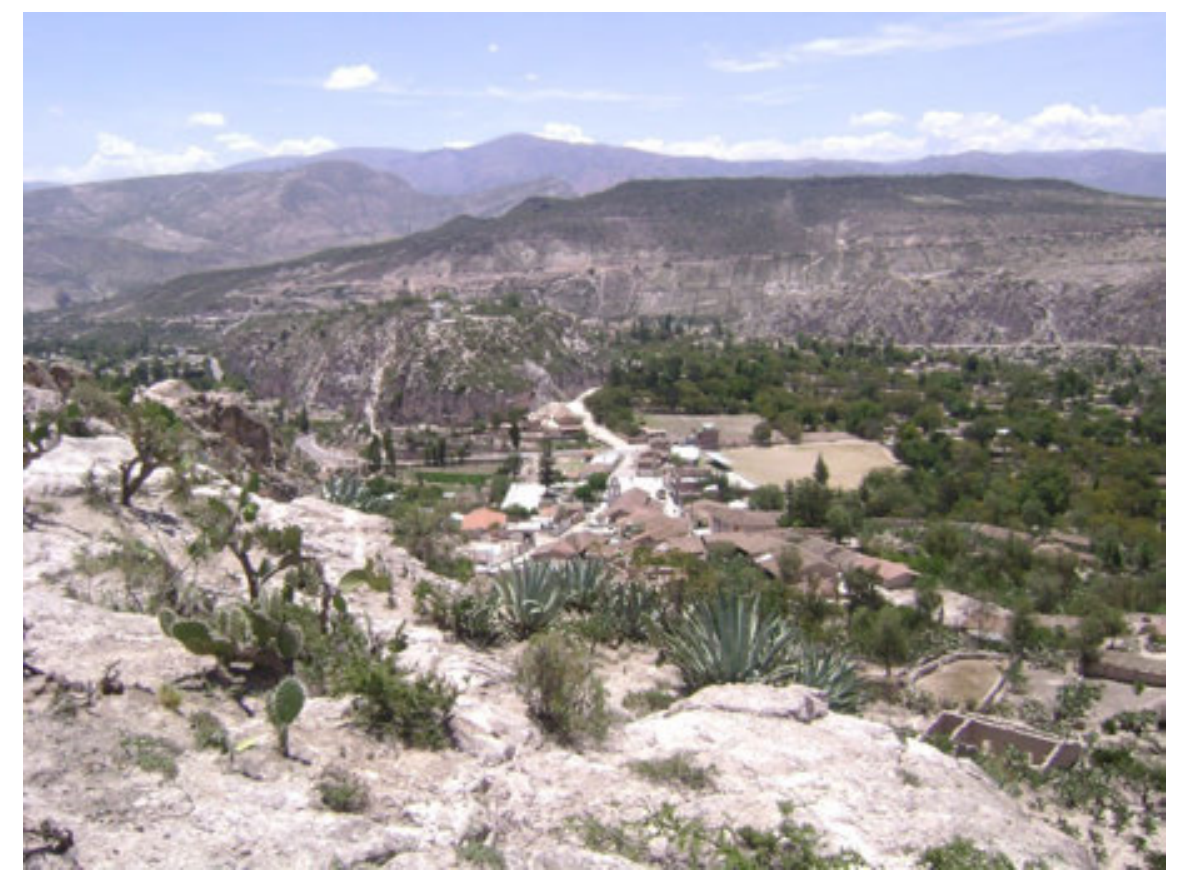

Figura 12. Primer plano $C^{\circ}$ Chupapata, segundo plano el pueblo de Pacaycasa $y$, en tercer plano $\mathrm{C}^{\circ}$ Tanta Orqo. 
tar una estructura ortogonal vista a manera de canchón de 72 x 77 m delimitado por altas murallas y plataformas en distintos niveles que la convierten en una eminente obra monumental producto de un trabajo mancomunado planificado (figura 13). En el lado sur exterior al canchón, se percibe una densa ocupación doméstica con abundante cerámica formando áreas contextuales específicas con fragmentos de cerámica que corresponden a los períodos Formativo, Desarrollos Regionales e Imperio Wari (figura 14), en sus diversos estilos y formas de vasijas; existen recintos de planta circular y manantiales cercanos. Algunas de las captaciones de agua presentan estructuras a modo de reservorios con canales de distribución, así como restos de caminos antiguos bien conservados como el que cruza de sur a norte la zona arqueológica, pasando por el lado oeste del canchón, partes del camino Wari, superpuesto a estructuras Huarpa, evidencias que ameritan ser estudiadas para un mejor conocimiento.

\section{La Vega}

Cerámica y material lítico disperso en un montículo ubicado al so del actual centro poblado de las Vegas (585259.9064E/8559296.3196N), 2907 m s. n. m., los fragmentos corresponden a los períodos Formativo, Huarpa y Wari y por las el lado SE del lugar pasa el trazo de un antiguo canal que viene desde Huamanguilla. Las evidencias se perciben en montículos y chacras contiguas, incluyendo el actual centro poblado alrededor del lecho de una antigua qocha (actual campo deportivo).

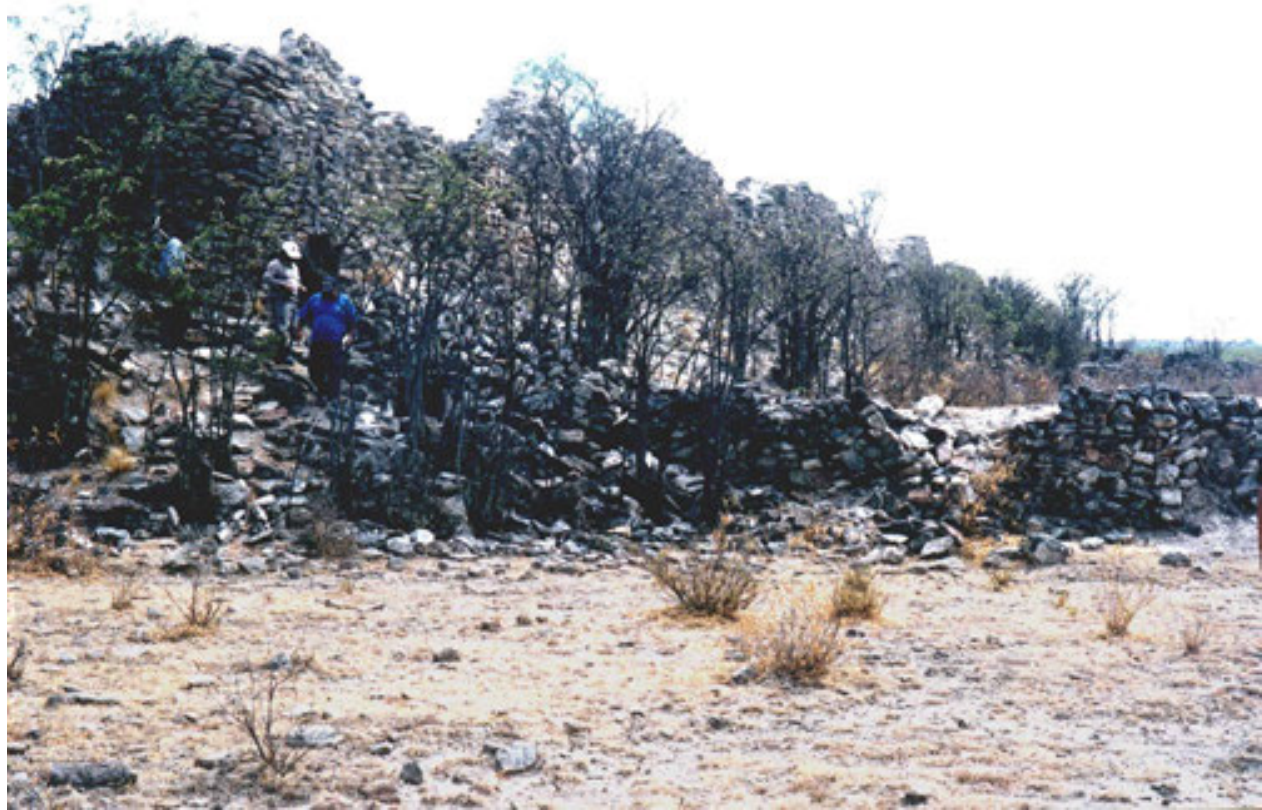

Figura 13. Muralla perimétrica de Tablapampa. 


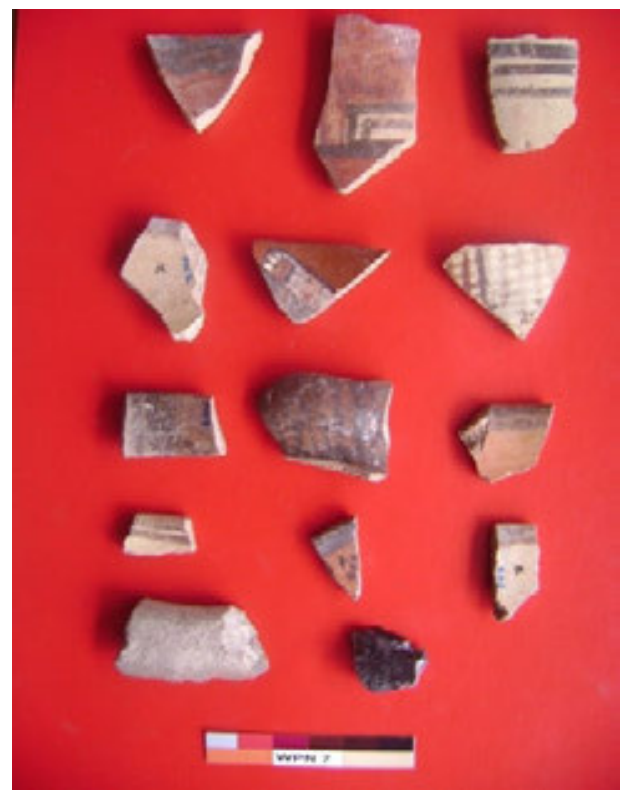

Figura 14. Cerámica Formativa, Huarpa, Huari y Cajamarca

\section{Marayniyoq}

Asentamiento establecido sobre una loma, cerca al centro poblado 24 de Junio (586519.7489E/8559423.3199N), 2961 m s. n. m., distrito de Huamanguilla, límite entre las provincias de Huamanga y Huanta, la estructura principal corresponde a la época Wari y consiste en un conjunto de piedras talladas y ensambladas unas a otras formando un aparente piso ceremonial, asociadas con estructuras menores de mampostería ordinaria con pequeños recintos, con pisos y paredes estucadas, una de las piedras que forma el piso presenta cavidades circulares a manera de pocitos ceremoniales, las piedras labradas presentan cierta semejanza de trabajo en piedra megalítica expuesta en diferentes sectores de la ciudad de Wari. En las chacras adyacentes existe cerámica del período Formativo, como parte de una ocupación inicial en el lugar que viene siendo investigado por Lidio Valdez Cárdenas desde el año 1999, quien ha realizado varias publicaciones.

\section{La Compañía (2550 m s. n. m.)}

Montículo contiguo al lado SE del cerro San Cristóbal (580441.8342E/ $8554769.2897 \mathrm{~N}), 2468 \mathrm{~m} \mathrm{~s}$. n. m., donde se ubica el actual cementerio del centro poblado de Chanchará-Compañia, el lugar aparece rodeado de terrazas seccionadas por la actual carretera que va a Huanta y Huancavelica, en la superficie del lugar se observa abundante cerámica de filiación formativa, Huarpa y Wari (figuras 15 y 16). 


\section{Tablarumi}

Cerro de formación alargada con afloramiento de roca del tipo tufo volcánico de coloración blanquecina, margen derecha de una quebrada, lado sur del centro poblado de Santiago de Paraíso (580827.4917E/8552897.729N), 2693 m s. n. m., las laderas si bien son escarpadas, existe angostos senderos que dan acceso a la cima y conexión con otros asentamientos, la cima es alargada con eje longitudinal suroeste-noreste, la parte más ensanchada es plana con cerámica de los periodos Formativo, Huarpa y Huari, disperso en un espacio aproximado de 1 a 1.5 has. Asociados a alineamientos de piedras que parecen corresponde a la cabecera o bases de recintos de aparente forma circular, que soportaban paredes de quincha. La ladera sur del cerro se conecta a otro cerro donde existe restos de un conjunto de terrazas para cultivo de secano, dispuestas de manera escalonada en varios niveles. Sostenemos que esta clase de andenes pertenecen al periodo Formativo (figura 17).

\section{Chaupyorqo}

Promontorio ubicado entre los cerros Tablarumi y Kichkaorqo, la cima es utilizado como cementerio del antiguo pueblo de San Juan de Viñaca ((582236.9186E/8553677.5575N), 2462 m s. n. m., margen izquierda del río Pongora o Compañía (figura 18). La cima y laderas, cubiertas de vegetación espinosa, impiden observar cabeceras de estructuras, pero si abundante apreciar abundante cantidad de cerámica de distintos estilos Huari, Huarpa y algunos del periodo Formativo Inferior o Cerámico Inicial.

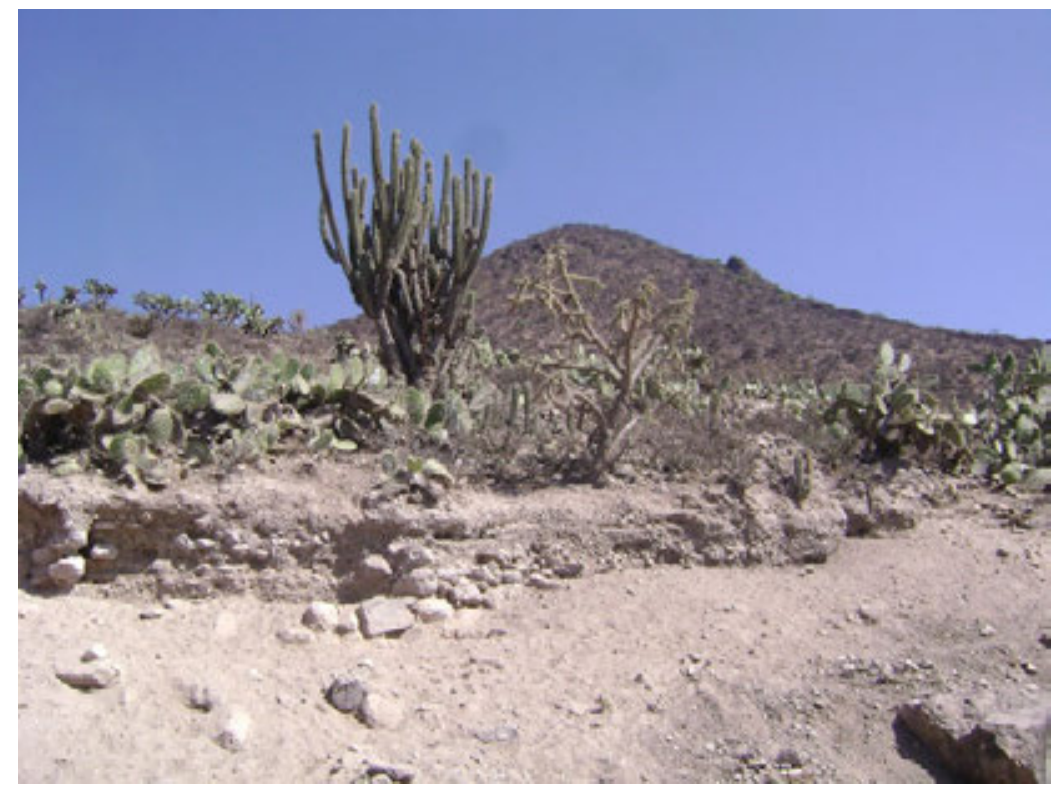

Figura 15. Panorámica del yacimiento 14 sobre la carreta Ayacucho-Huanta-Huancavelica. 


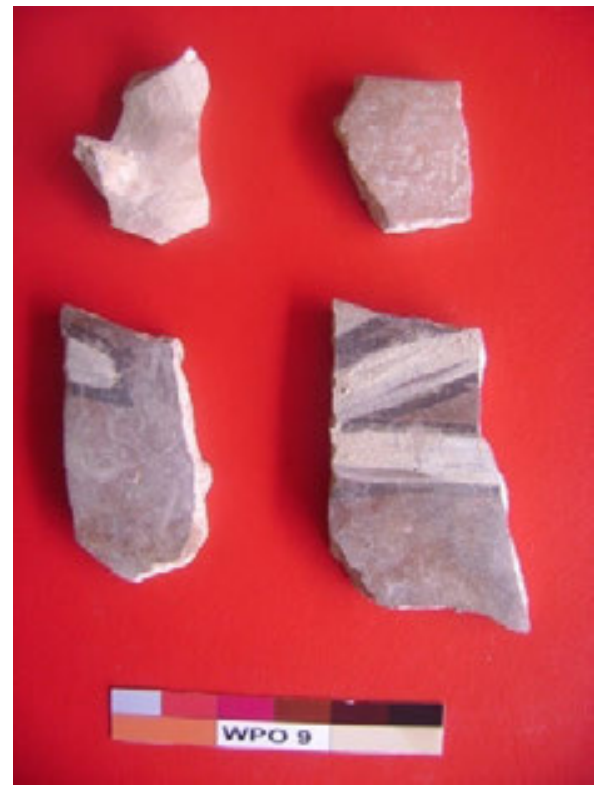

Figura 16. Cerámica Formativa y Huarpa tricolor.

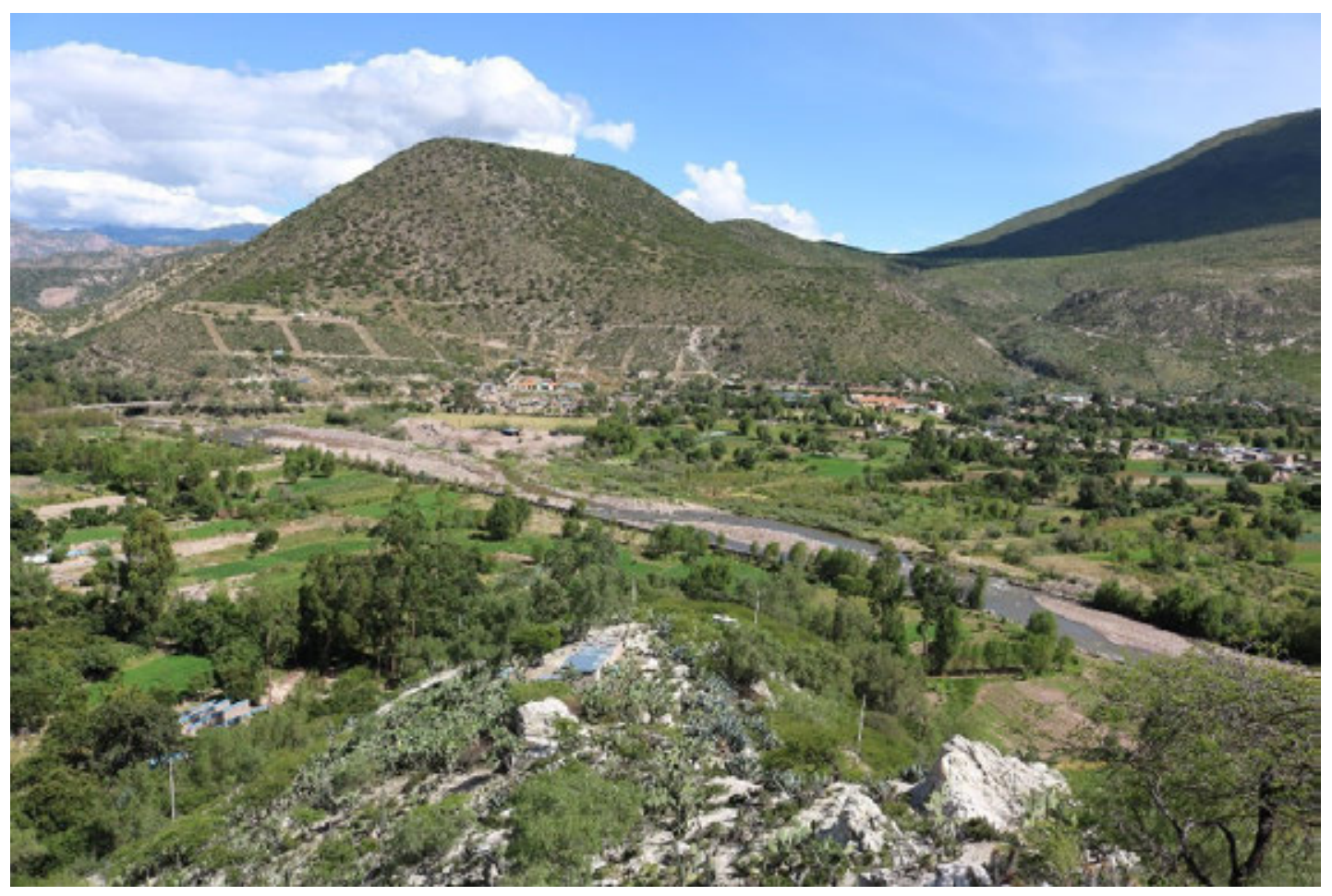

Figura 17. Panorámica donde se aprecia en primer plano el asentamiento de Tablarumi, margen izquierda del río Compañía-Viñaca. 


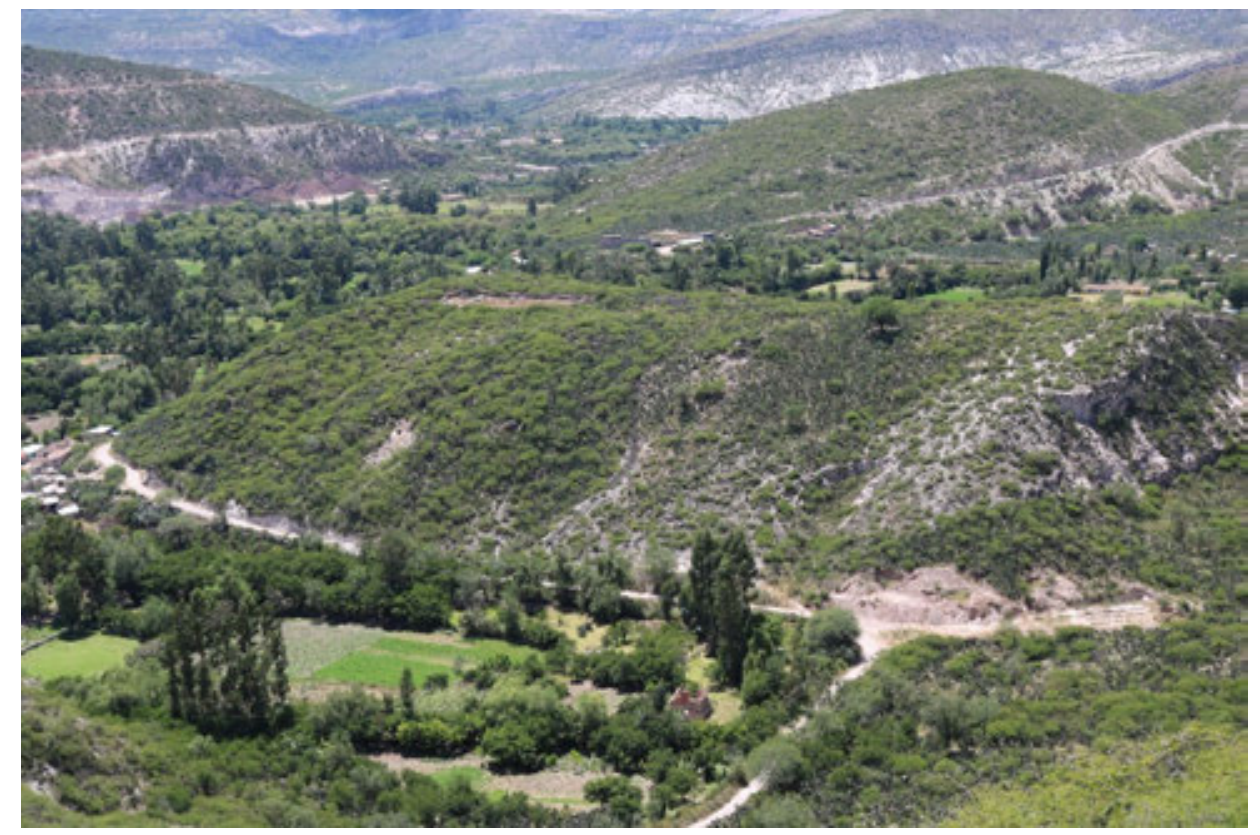

Figura 18. Ubicación de los yacimientos de Chaupiorqo sobre la carretera y al fondo Kichkaorqo, ambos en la margen izquierda del río Pongora conocido aguas abajo como Viñaca.

\section{Kichkaorqo}

Cerro de mayor elevación, (582096.4994E/ 8552746.112N), 2638 m s. n. m., separado de promontorio de Chaupiorqo por el lecho de una quebrada seca, por donde pasa la carreta que corta la ladera norte, en cuyos perfiles se perciben secciones de muros y una amplia y densa población prehispánica dispersa en más de 6 has, que corresponde a la ladera que desciende al río Pongora o Compañía, la parte baja presenta restos de canales y chacras antiguas reutilizadas por los actuales pobladores con cultivos hortalizas y árboles (figura 18). La superficie del cerro si bien está cubierta de huarangos y cactáceas, se observa abundante cerámica y artefactos líticos entre los que figuran fragmentos de cuerpos, bases, asas de una variedad de vasijas de los períodos Formativo (inferior), Desarrollos regionales (Huarpa) y del imperio Wari (estilos Huamanga, Chaquipampa y Viñaque). Por la extensión o magnitud pensamos que fue el poblado con mayor población en la margen izquierda del río Pongora.

\section{Huarancayoc}

Colina alargada dispuesta en la margen derecha del río Chacco, sobre la carretera, altura de la antigua iglesia del centro poblado de Chacco (figura 19: 6), la cima es una planicie que se extiende hasta la altura del actual cementerio, delimita hacia 
el norte por la quebrada Checclla Huayqo (585566.8236E/8552489.741), 2571 m s. n. $\mathrm{m}$., en toda la extensión de la planicie sobresalen tres promontorios; dispuestos de este a oeste, con abundante cerámica del período Formativo, siendo el promontorio del medio donde se puede percibir mayor proporción de elementos diagnósticos, asociado a restos de terrazas (figuras 20 y 21).

\section{Lagunilla}

Terrazas agrícolas y alineamientos de estructuras cortadas por la carretera Ayacucho Huanta desde la repartición de la carretera que va a Huancavelica, pasando por los poblados de la Compañía, Chancauylla, Simpapata, Viñaca, etc., hasta el desvío de la carretera Huanta-San Francisco (583905.7607E/8553958.7550N), 2464 m s. n. m., la superficie del área que incluye parte del poblado de Huayllapampa y bosque de algarrobos junto a la pampa o qocha de lagunilla presenta cerámica de los periodos Formativo, Huarpa y Huari., así como estructuras que parecen corresponde a viviendas (figura 22).

\section{Chipingura}

Cerámica dispersa en una chacra localiza en la confluencia de la quebrada Chipingura con otra pequeña quebrada, al norte de la colina de Churucana, altura del camino de herradura que va de Pampachacra a Llamahuillcca (591095.8855E/591095.8855N), 2990 m s. n. m. La cerámica encontrada es del período Formativo, pero también hay algunos fragmentos Huarpa y Wari.

\section{Arcaico}

Ladera de suave pendiente, margen izquierda de una pequeña quebrada que alimenta de agua a la quebrada Checclla Huayqo, límite sur del Complejo Arqueológico Wari $(589115.3388 \mathrm{E} / 8554878.1451 \mathrm{~N}), 2860 \mathrm{~m}$ s. n. m., superficie del terreno con fragmentos de cerámica de los periodos Formativo, Desarrollos Regionales y del Imperio Wari, sin arquitectura visible, a pesar que el terreno aparece erosionado por las lluvias.

\section{Senqopampa}

Llanura de aproximadamente $1 \mathrm{~km}$ de largo por $200 \mathrm{~m}$ de ancho, ubicada en las inmediaciones de vista Alegre (586978.5595E/8554146.6236N), 2695 m s. n. m., margen derecha de la quebrada Mituqasa / Checlla Huayqo. La planicie contiene restos de una densa población humana que ocupó el lugar desde el periodo Formativo hasta la época Wari (figuras 23 y 24). La superficie del sitio presenta estructuras habitacionales, tumbas de forma cilíndrica excavadas bajo la roca madre, terrazas con amplios espacios abiertos, abundantes fragmentos de cerámica y líticos, destaca algunas for- 

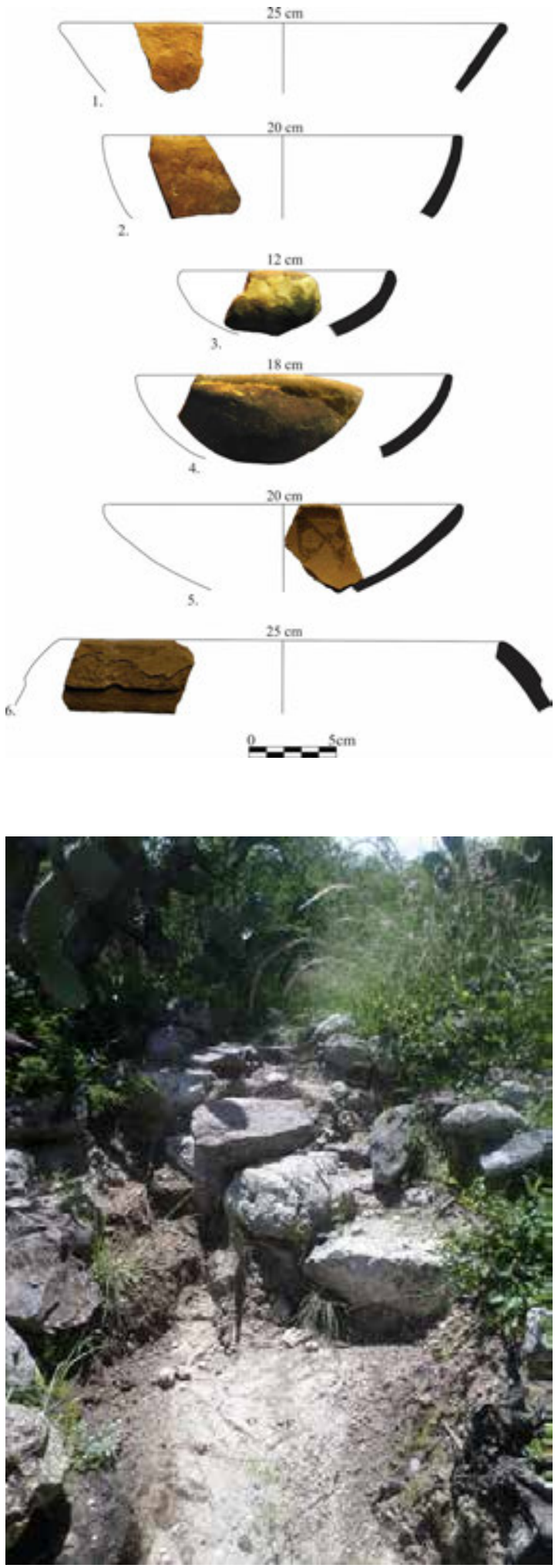

Figura 19. Estilo Andamarca: 1 (Sitio Yuraq Loma en Stgo de Pischa); 2 (Molinuyoc sobre Pikimachay); 3, 4, 5 (Magnu), y 6 (Huarancayoc). Referencia: Canchari, 2018.
Figura 20. Estructuras formativas del $C^{\circ}$ Huarancayoq 

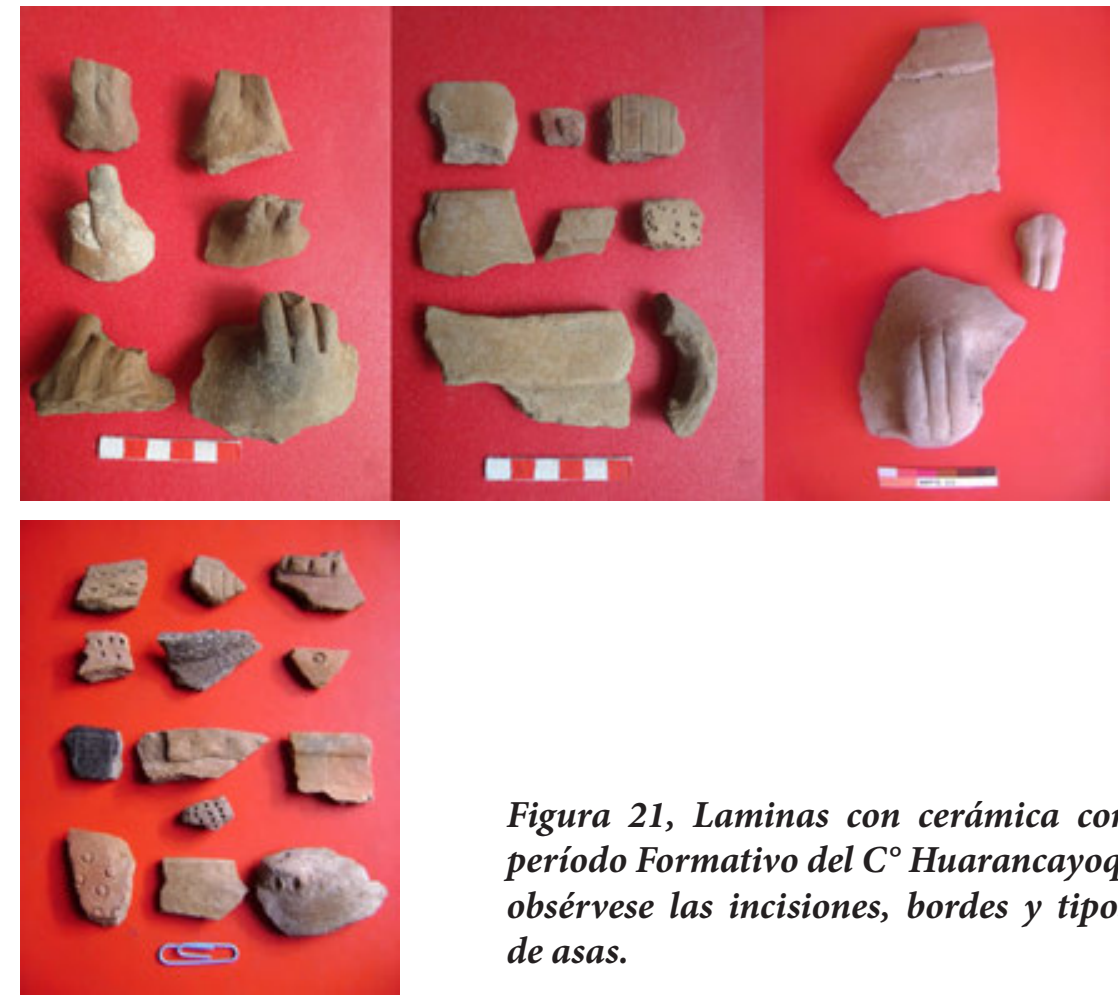

Figura 21, Laminas con cerámica con período Formativo del $\mathrm{C}^{\circ}$ Huarancayoq, obsérvese las incisiones, bordes y tipos de asas.

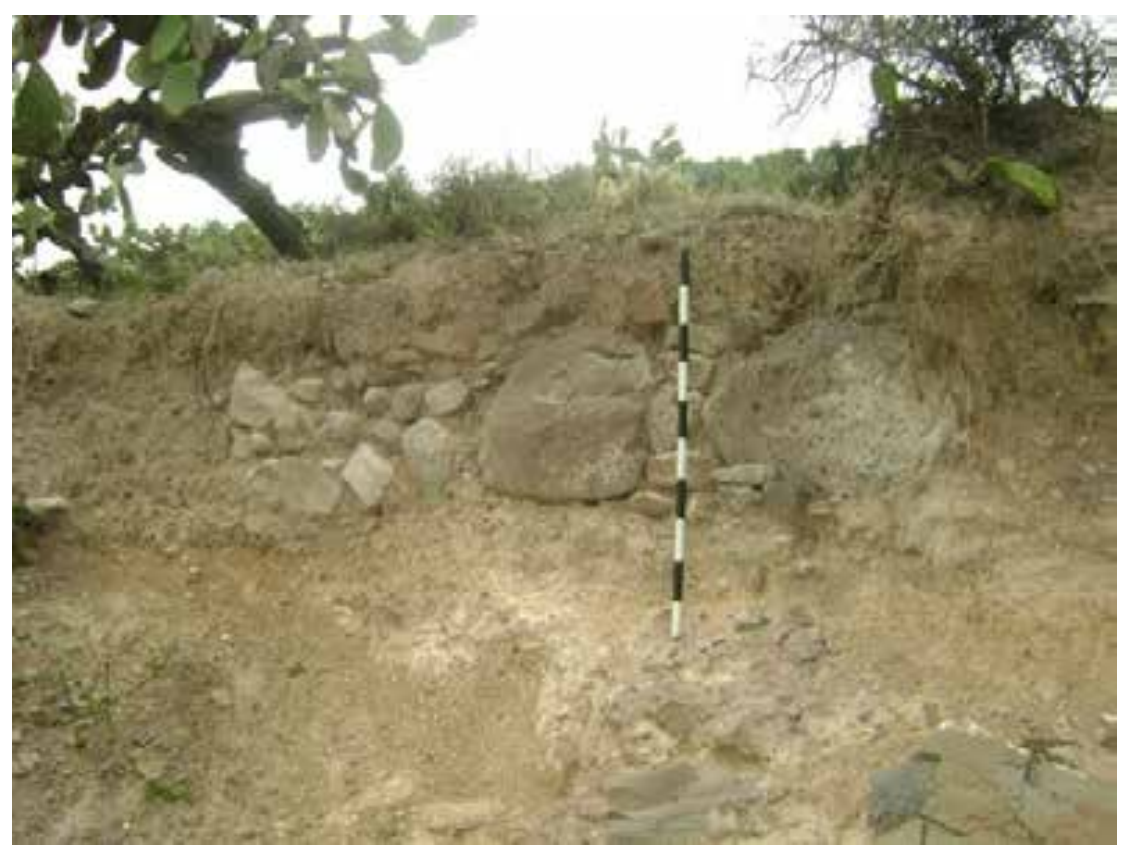

Figura 22. Muros de contención de terrazas agrícolas del formativo Superior 


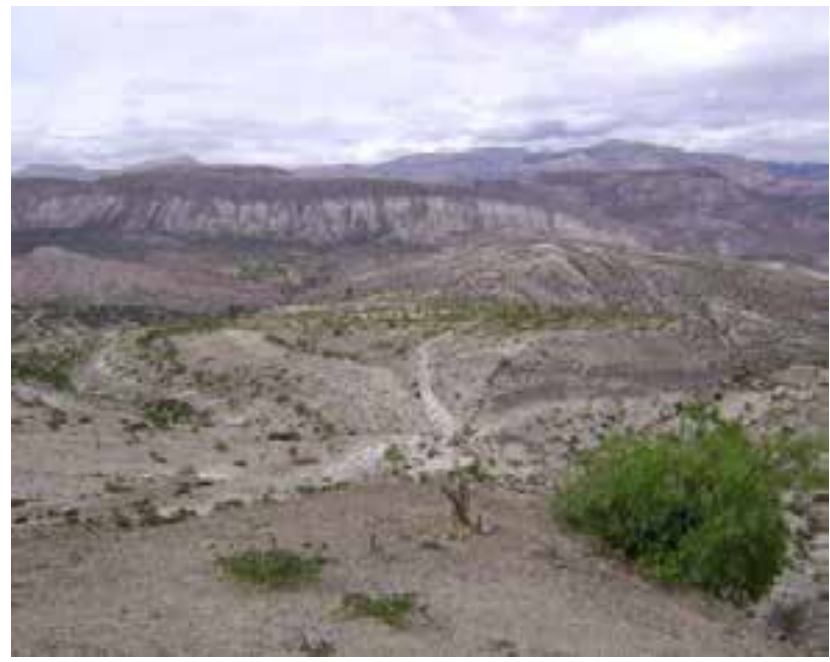

Figura 23. Planicie de Senqopampa al sur de la zona Urbana Wari.

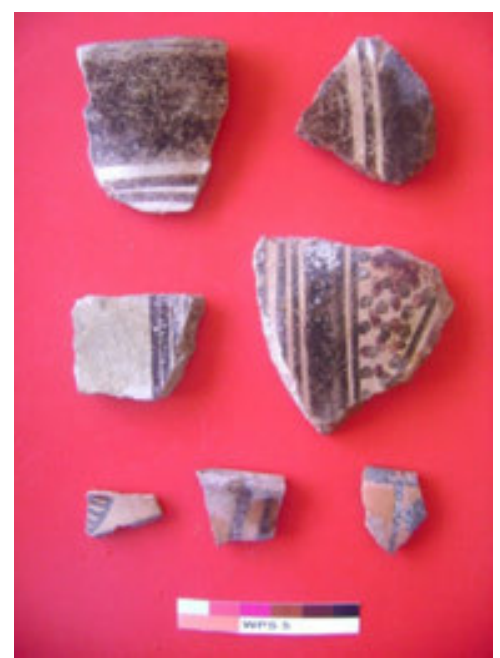

Figura 24. Huarpa Negro sobre Blanco, Negro sobre Ante y Tricolor.

mas de vivienda de uso doméstico a lo que se incluye la presencia de cerámica Cajamarca cursivo floral.

\section{Pampachacra}

Cerámica dispersa en medio de chacras de cultivo en ambos lados del espacio cortado por la carretera Ayacucho-Quinua, principalmente junto al actual campo deportivo, así como en los terrenos de la familia Huaraca (590228.3923E/8555971.893N), $2948 \mathrm{~m}$ s. n. m. Los fragmentos corresponden a los periodos Formativo, Huarpa y Wari (figura 25).

\section{Vista Alegre (2 780 m s. n. m)}

Promontorio que ocupa el lado sur del centro poblado de vista Alegre (587652.0863E/8554813.1219N), 2749 m s. n. m., presenta en la superficie cerámica de los períodos Formativo, Huarpa, Wari (figuras 26 y 27), incluyendo Cajamarca III, fragmentos de obsidiana, turquesa, etc.

\section{Suyturumi}

Sitio localizado en la margen izquierda del curso medio de la quebrada Ocros (586498.924E/8555430.343N), 2663 Cerámica de filiación formativa, Huarpa y Wari, dispersa en chacras y montículo pedregoso de la zona conocida como Suyturumi, lugar donde existe petroglifos en las variedades de pocitos circulares, culebras, espirales, etc. 


\section{Pikimachay}

Cueva ubicada en la ladera del cerro Molinuyoq / Leqlespata / Ccorihuayruna (583684.2808E/8558472.6342N), 2917 m s. n. m., distrito de Pacaycasa. Fue explorada y excavada bajo la dirección del Dr MacNeish entre 1968 y 1970, quien basado en la estratigrafía y datación de carbono 14, define una secuencia cultural desde la los inicios de la fase Pacaicasa (20 000 a. C.) hasta los finales de la fase Huanta (9000 a. C.) con un abandono de 2000 años para luego ser reocupada desde la fase Jaywa (7000 a. C.) hasta la época de la etnia de los Quinua, contemporánea con los Chankas e Incas, con aparente abandono en las fases Andamarca y Kickapata (1750-600 a. C.), periodo Formativo. Inferior y Medio (figura 28). Referencia: MacNeish, et. al (1981).

\section{DISCUSIÓN}

La distribución espacial de los yacimientos y estructuras del período Formativo, registradas en el área del Complejo Wari y periferia inmediata indican que los lugares preferidos para ocupación cultural, eran la cimas de cerros, promontorios, laderas, cuevas y abrigos cercanos a fuentes de agua y canteras de arcillas plásticas y antiplásticos, para la producción alfarera y labores agrícolas con cultivos de maíz, frejoles, calabaza, zapallos, quinua y árboles frutales como pacae, lúcuma, chirimoya, guayaba, etc., los sitios están relativamente alejados de zonas de riesgo (huaycos). Todos estos asentamientos representan de manera general la introducción de la cerámica en Ayacucho, con atributos decorativos de incisiones, puntuaciones, aplicaciones, muescas, etc., ajenos a Chavín, vinculada con el estilo Andamarca definido por Lumbreras (1974) y MacNeish et, al (1981), MachNeish (1981), que caracterizan a la cerámica del periodo Formativo Inferior llamado también Cerámico Inicial, que se dispersó en los Andes peruanos entre los 2000 a 1000 a. C., creando una suerte de integración regional en el segundo antes de la presente era cristiana.

En Huamanga el Formativo Inferior está representado por la fase Andamarca (1750 y 1250 a. C.), que abarca la Capa J, K, M y L de Wichqana; capas D2, D1 y DD de Solar Moqo o Usno Era y D de Raqay Pampa, que contenían cerámica del tipo Andamarca o Pre Chavín, caracterizada por ser de coloración anaranjada, la cual si bien era poca, pero muy bien lograda con hornos con oxidación; la cerámica es compacta y en algunos casos muestra pintura roja en bandas sobre la superficie pulida, Lumbreras (1974) señala que esta clase de cerámica puede tener relación con una cerámica similar de la costa central, agrega además que de la fase Andamarca no se tiene evidencias de cómo eran sus casas y muy poco sobre sus instrumentos y habilidades. Hablar del Formativo Inferior en Ayacucho es referirse a Qarqampata Temprano o inicial, formalmente semejante a la cerámica Wayrajirca, Guañape Medio, las Aldas, Tortugas, Hacha, Tutiscainyo, Marcavalle y Qaluyo, Wayhuaca, Muyo Moqo, entre otros sitios de los Andes y Sierra centro sur andina. 
Hasta dónde venimos estudiando el Complejo Arqueológico Wari y entorno, en base a cerca de medio centenar de sitios con cerámica del periodo formativo inferior o cerámico Inicial, podemos sostener que aproximadamente el $90 \%$, presentan evidencias de haber sido reocupados en las fases siguientes del período Formativo, es decir en los períodos los Desarrollos Regiones e Imperio Wari, representados por una serie de estilos y formas alfareras, excepto de algunos sitios como Churucana, Cerro Churo, Cerro San Cristóbal, Cerro Magnu y Molinuyoq, que incluso testimonian haber sido reocupados durante el periodo de los Estados Regionales, vinculados con tradiciones locales como los quinuas, etnia que ocupó el antiguo territorio de actual provincia de Huamanga( Espinoza, 2015), contemporáneos con los Chankas e Incas, esta última versión requiere ser contrastada con la investigación arqueológica a fin de aclarar cronológicamente este período tardío, de tal manera que los fragmentos atribuidos, obedece a una comparación con los estilos Arqalla, Qachisqo Tanta Orqo y Aya Orqo atribuidos a la confederación Chanka, aun cuando Qachisqo y Aya Orqo podrían corresponder a fases tempranas.

El Formativo Medio u Horizonte Temprano, está representado por la influencia Chavín y Cupisnique, documentado en las excavaciones de Chupas y Wichqana por Lumbreras $(1974,1981)$, En Jarqampata por Ochatoma (1985 a-b), en Ñawumpuquio (Machaca 1987), en Iraqata (Mancilla 2008), en Campanayoq Rumi (Matsumoto y Cavero 2009), en Churucana (Huamaní, 2014, Cavero y Huamaní, 2017) en Paullaucha (Mendoza, 2017) y Waychaupampa (Pérez y Paredes 2016, Pérez y Quispe, 2019), en el caso de la colina de Churucana, en la parte alta del Complejo Wari, aparece asociado con restos de arquitectura monumental de barro, mientras que en Waychaupampa cerca de Ayacucho, a restos de piso quemado de una probable estructura ceremonial. En Pallaucha, es más tardío según Mendoza (2017), quien hace referencia de distintos tipo de cerámica vinculados con la tradición Paracas. También existe un tipo de cerámica Tricoloor encontrada en las excavaciones de del sitio formativo de Waychaupampa y en la superficie del yacimiento de Magnu (sitio 5 del presente trabajo), que según Quispe (2018) y Canchari (2018), corresponde al tipo Tunasniyoq en referencia a la cerámica definida por Lumbreras y MachNeish (1981). En el valle de Ayacucho la fase Chupas como representante del Formativo Medio en Ayacucho resulta ser contemporáneo con Sechín, Moxeque, Cupisnique, La copa (Kuntur Wasi), Chongoyape, Cotosh, Ancón y Supe.

A la identificación y registro de yacimientos y estructuras descritas en párrafos anteriores se agregan otros que por la extensión del artículo no se ha incluido de manera separada, pero para fines de investigación resulta necesario tener conocimiento de existencia de otros yacimientos como las evidencias encontradas en la cima del cerro Molinuyoq sobre los 3900 m s. n. m.; Ancohuilca en la laderas orientales del Molinuyoq, este sitio fue registrado por el Dr. Tello en su primera visita que hiciera a Wari en compañía de Lila O’Neale. Entre la Vega y Pacaicasa existe 
varios zonas con material Formativo, caso de la ladera que rodea al asentamiento de Tablapampa, asi como la planicie de Quirura, próxima a Huamanguilla, en el lado sur de Wari, entre cerro Churo y Huarancayoc esta Miqtuasa cuya superficie de la chacras anexas contienen material Formativo, de igual manera se puede advertir la presencia del Formativo en varios de los montículos de la parte alta y baja de Wari que se encuentran cubiertos de tunales y que obstaculizan la observación "in situ" de los materiales. De igual forma los montículos que rodean al cerro Huaqanmarca, por donde cruzan los caminos antiguos de acceso a la metrópoli Wari. Todos con reocupación Huarpa y Wari.

Por otro lado, se sostiene que la presencia de cerámica del período Formativo en alta y baja de la zona urbana de la ciudad de Wari, cortada por el cauce longitudinal de la quebrada Ocros, permite pensar en un temprano sistema dual de organización y distribución espacial de la indicada ciudad.

Agradecimiento: En las salidas de campo participaron varios estudiantes (ahora bachilleres) de la Universidad Nacional de San Cristóbal de Huamanga, como Teodoro Cconoc, Katherinne Aylas, Pedro Arce, quienes vienen explorando distintas partes de los valles de Huamanga y Huanta, propensos a ser destruidos la acelerada expansión poblacional y construcción de obras públicas.

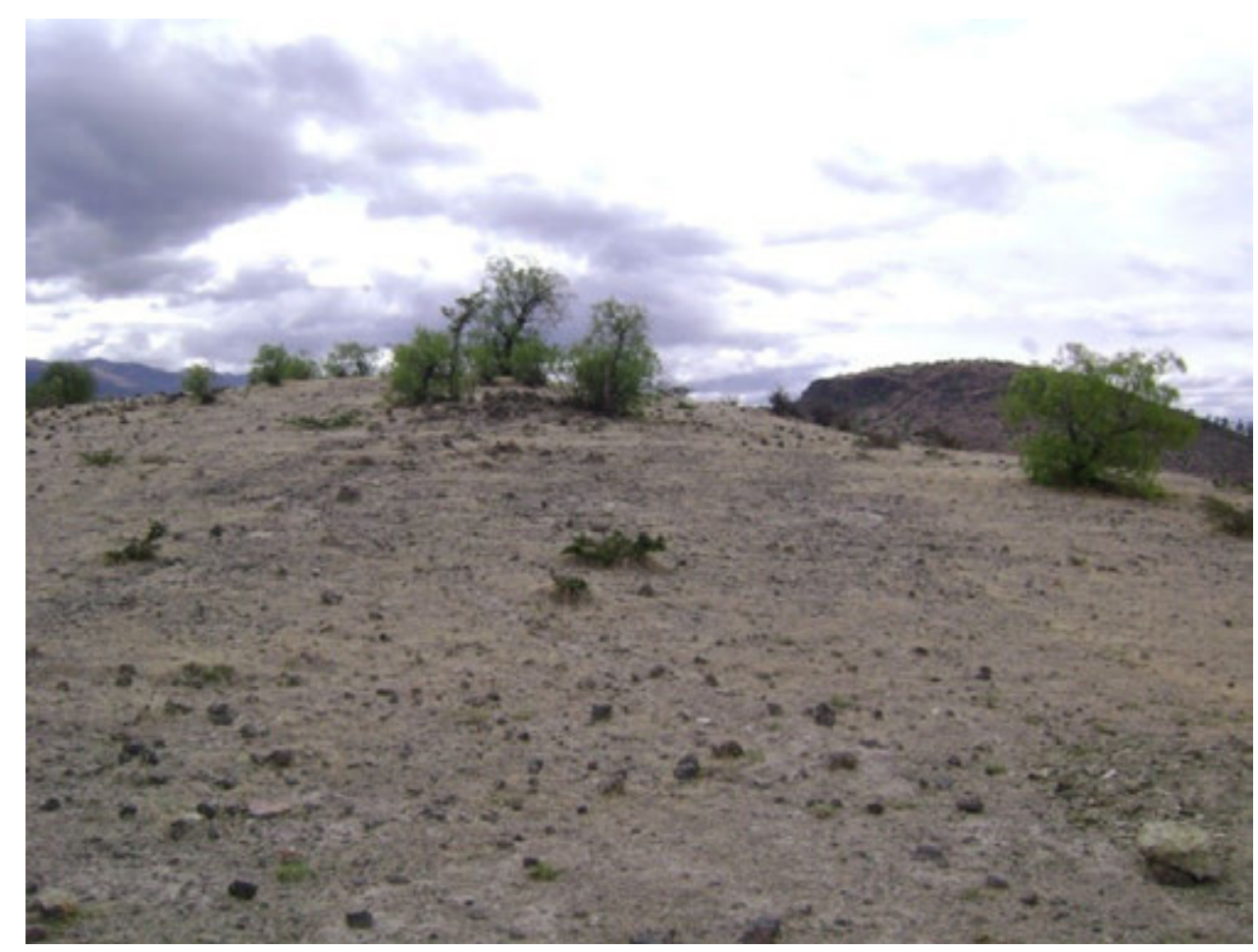

Figura 26. Montículo con cerámica Formativa, Huarpa y Wari en Vista Alegre 


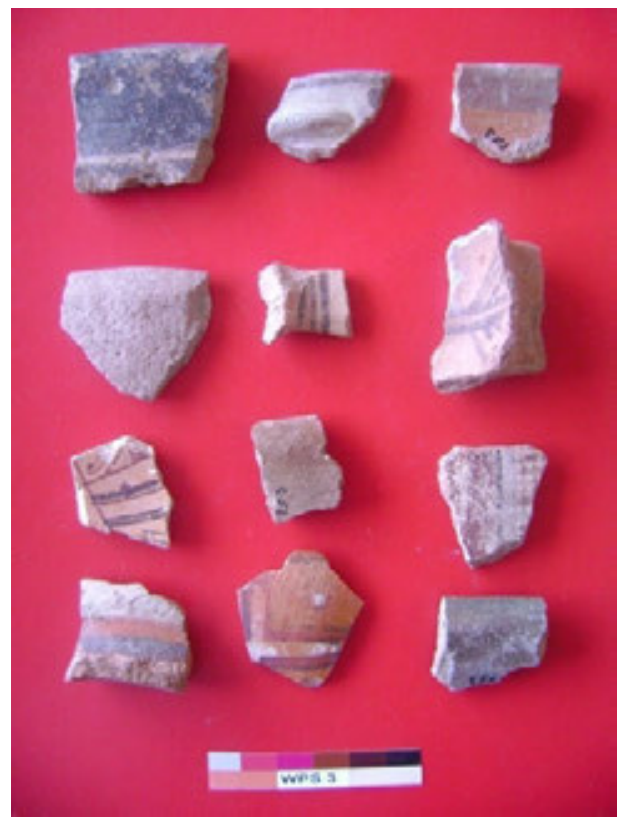

Figura 27. Cerámica del Formativo, Huarpa Negro sobre Blanco, Tricolor, Ocros, Chaquipampa, Negro Decorado, Cajamarca

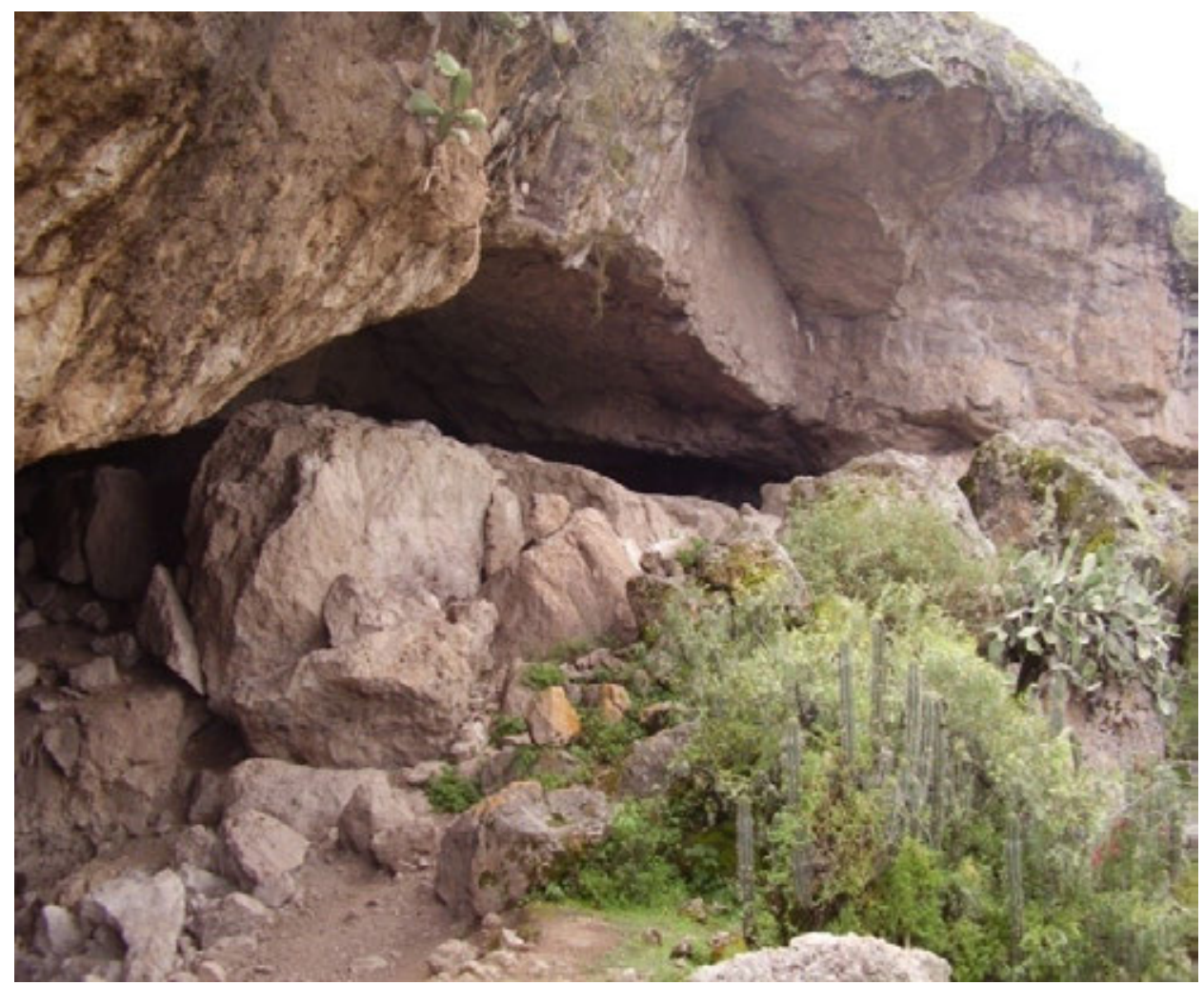

Figura 28. Panorámica de Pikimachay (cueva de la pulga) 


\section{REFERENCIAS BIBLIOGRÁFICAS}

Bonavia, D. (1966). Sitios arqueológicos del Perú (Primera parte). Arqueológicas (9), 3-71. Museo Nacional de Antropología y Arqueología, Pueblo Libre, Lima.

Benavides, M. (1976). Yacimientos Arqueológicos en Ayacucho. Departamento de Ciencias Histórico Sociales. Universidad nacional de San Cristóbal de Huamanga, Ayacucho.

Benavides, M. (1984). Carácter del Estado Wari. Universidad Nacional de San Cristóbal de Huamanga, Ayacucho.

Bennett, Clark W. (1953). Excavations and Wari, Ayacucho, Perú. Yale University. Publications in Antropology Number 49. New Haven.

Canchari Castro, A. (2018). La alfarería de la época Wari: análisis e interpretaciones. Tesis de para Obtener el Título de Licencia en Arqueología. Facultad de Ciencias Sociales, Universidad nacional de San Cristóbal de Huamanga.

Casafranca, J. (1960). Los nuevos sitios Chavinoides en el departamento de Ayacucho. Revista Antiguo Perú: Espacio y Tiempo (pp. 325-333). Editorial Juan Mejía Baca. Lima

Cavero Palomino, Y. y Huamaní Díaz, R. (2015). Empleo de adobes como material constructive durante el Período Formativo e Intermedio Temprano en Churucana, Ayacucho. Arqueología y Sociedad, (24), 285-320. Museo de arqueología y antropología, Universidad Nacional mayor de san Marcos.

Cieza de León, P. (1973). La crónica del Perú. Ediciones Peisa Lima. ( Original publicado en [1550]).

Flores, B. (1944). Investigaciones arqueológicas. Revista Huamanga (8), 7-14. Ayacucho.

Doi, Masaki. (2002). (ms). Informe preliminar del Proyecto de prospecciones arqueológicas en los valles de Ayacucho y Huanta, Perú, 2001. Instituto Nacional de cultura, Ayacucho.

Flores, I. (1960). Wichqana Sitio temprano en Ayacucho. Revista Antiguo Perú: Espacio y Tiempo (pp. 335-343). Editorial Juan Mejía Baca. Lima.

González Carré, E. y Bragayrac, Enrique. (1983). El área ceremonial en la ciudad de Wari: Una Hipótesis. INC/Corporación de Fomento y Desarrollo Económico Social, Ayacucho.

González Carré, E. y Bragayrac, E. (1986). El templo Mayor de Wari. Boletín de Lima (47), 9-20. Editorial, los Pinos, Lima.

González Carré, E., Bragayrac Davila, E., Vivanco Pomacanchari, C., Tiesler B., Vera Lopez Quispe, M. (1995). El Templo Mayor de la ciudad de Wari. Estudios arqueo- 
lógicos en Vegachayoq Moqo, Ayacucho. Oficina de Investigación. Laboratorio de Arqueología, Facultad de Ciencias Sociales, Universidad Nacional de San Cristóbal de Huamanga.

González, Enrique-Gálvez, J. (1987). Molinuyoq: Terrazas y reservorio en un pueblo Prehispánico de Ayacucho. Boletín de Lima (53), 19-24, Editorial Los Pinos E.I.R.L. Lima.

Huamaní, J. R. (2014). Estudio de las evidencias arqueológicas halladas en el cerro Churucana, distrito de Quinua, Ayacucho. Tesis de Licenciatura, Facultad de Ciencias Sociales, Universidad Nacional San Cristóbal de Huamanga.

Isbell William H. (2001). Huari: Crecimiento y desarrollo de la ciudad Imperial. Wari Arte Precolombino Peruano (pp.99-172). Centro Cultural el Monte, Sevilla.

Isbell, W., Brewster-Wray, C. y Spickard, Lynda E. (1991). Huari Administration and the Orthogonal Cellular Architecture Horizon. En Isbell and G.F. McEwan (Eds.). Huari Administrative Structure. Prehistoric Monumental Architecture and State Government (pp. 293-315). W. H. Washington D. C. Dumbarton Oaks.

Isbell, W., Pérez, I. y Wolff, B. (2017). Proyecto de Investigación Arqueológica "Prehistoria Urbana de Huari, Temporada 2017", Informe Final, presentado al Ministerio de Cultura.

Lumbreras, L. G. (1959). Sobre los Chancas. Actas del II Congreso Nacional de Historia del Perú. Tomo I, (pp. 211-242). Lima.

Lumbreras, L. G. (1959). La Cultura de Wari, Ayacucho En: Etnología y Arqueología, Año 1, (pp. 130-227). Facultad de Letras, Universidad Nacional Mayor de San Marcos. Lima.

Lumbreras, L. G. (1969). De los Pueblos, las culturas y las artes del antiguo Perú. Moncloa Campodónico Editores Asociados.

Lumbreras, L. G. (1974). Las Fundaciones de Huamanga. Edición en Homenaje al Sesquicentenario de la Batalla de Ayacucho. Editorial Nueva Educación, Lima.

Lumbreras, L. G. (1981). The Stratigraphi of the Open sites. Prehistory of the Ayacucho Basin, Perú. Volumen II Excavations and Chronology. En MacNeish et, al. (Eds) (pp. 167-198). Published for the Robert S. Peabody Foundation for Archaeology, The University Of Michigan Press, Ann Arbor.

Macneish, R. S. (1981). Synthesis and Conclusions. Prehistory of the Ayacucho Basin, Perú. Volumen II Excavations and Chronology (MacNeish et, al., (Eds.) (pp. 199266). Published for the Robert S. Peabody Foundation for Archaeology, The University Of Michigan Press, Ann Arbor. 
Machaca Calle, N. (1997). Secuencia cultural y nuevas evidencias de formación urbana en Ñawimpukio. Tesis de Licenciatura, Facultad de Ciencias Sociales, Universidad Nacional de San Cristóbal de Huamanga.

Mancilla Mantilla, R. (2008). Ira Qata, un sitio del Formativo en Ayacucho. Tesis de Licenciatura, Facultad de Ciencias Sociales, Universidad Nacional de San Cristóbal de Huamanga.

Matsumoto, Y. y Cavero, Y. (2009). Una aproximación cronológica del centro ceremonial de Campanayuq Rumi, Ayacucho, (Kaulicke / Onuki (eds.), El Período Formativo: enfoques y evidencias recientes. Boletín de Arqueología PUCP (13), 323-346. Lima.

Medina, Pio Max. (1931). Descubrimientos de Tumbas Arqueológicas. Boletín de la Sociedad Geográfica de Lima, tomo XLVIII, trim.1 (pp. 45-72); trim. 2 (pp. 101-112).

Mendoza Martinez, E. (2017). Secuencia de cerámica Paracas en Pallaucha, Vilcashuaman. Boletín de Arqueología PUCP $\mathrm{N}^{\circ} \mathrm{N}^{\circ}$ 22: 91-116, Lima.

Ochatoma Paravicino, J. (1985a). Jarqan Pata de Huamanga: Investigaciones arqueológicas en un yacimiento correspondiente al Horizonte Temprano. Informe de Seminario de Investigación Arqueológica III. Facultad de Ciencias Sociales, Universidad Nacional de san Cristóbal de Huamanga.

Ochatoma Paravicino, José. (1985b). Acerca del Formativo en la Sierra Centro Sur. Tesis de Licenciatura, facultad de Ciencias Sociales, Universidad nacional de san Cristóbal de Huamanga.

Ochatoma Paravicino, J. (1992). Acerca del Formativo en Ayacucho. Estudios de Arqueología Peruana, D. Bonavía (Ed.) (pp. 193-214), Fonciencias, Lima.

Ochatoma Paravicino, J. (1998). El Formativo en Ayacucho: balances y perspectivas. Boletín de Arqueología PUCP N²: 289-302. Perspectivas regionales del Período Formativo en el Perú.

Ochatoma, J., Pariahuaman, A. y Larrera, U. (1984). ¿Cupisnique en Ayacucho?. Gaceta Arqueológica Andina Nº 9: 10. INDEA, Lima.

Pérez Calderón, I. (2003). Arquitectura planificada Huari, en la periferia de la ciudad capital. IV Jornada de investigación Universitaria 2003, (pp. 89-96). Oficina de Investigación, Universidad Nacional de san Cristóbal de Huamanga, Ayacucho

Pérez Calderón, I. (2005). Evaluación arqueológica carretera Ayacucho-San Francisco, tramo km 0.00 (Dv. Huanta), km 26 (Quinua), Convenio de Cooperación Interinstitucional entre el Instituto Nacional de Cultura y Provias Nacional, Informe Final presentado al INC. 
Pérez Calderón, I. (2007). Asentamientos periféricos de la metrópoli Huari. Ruta Cultural del Perú. Tomo II: 319-330, Wilfredo Kapsoli/editor. Asamblea nacional de rectores, Lima.

Pérez Calderón, I. (2013). Arqueología del espacio Wari-Ayacucho: 200-600 d. C (Primera parte). Boletín de Lima N 171: 19-34. Editorial El Pino E.I.R.L. Lima.

Pérez Calderón, I. (2014). Arqueología del espacio Wari-Ayacucho: 200-600 d.C (Primera parte). Boletín de Lima No 172: 11-87. Editorial El Pino E.I.R.L. Lima.

Quispe Robles, M. (2018). Revaluación del Formativo a partir del análisis del material cultural asociado a la U-I de Waychaupampa, Ayacucho. Tesis de Licenciatura, Facultad de Ciencias Sociales, Universidad Nacional de San Cristóbal de Huamanga.

Rowe, J., Collier, D. y, Willey, G. (1949). Reconnaissance Notes on the Site of Huari, Near Ayacucho Perú, American Antiquity, 16(2), 120-137 Salt Lake City".

Rowe, J. (1958). Tiempo, Estilo y Proceso Cultural en la Arqueología Peruana. Revista Universitaria Año XLVII, Segundo Semestre $N^{\circ} 1$ (pp. 79-96). Universidad Nacional san Antonio Abad del Cusco.

Tello, J. C. (1969). “Las Ruinas de Huari”. 100 Años de Arqueología en el Perú (pp 519525). Editado por Petróleos del Perú. Instituto de Estudios Peruanos. Lima.

Tello, J. C. (2014). Cuadernos de Investigación del Archivo Tello No 12. Expedición al Vilcamayo, 1942. Primera parte: Sierra Central y Cusco. Museo de Arqueología y antropología, UNMSM

Valdez Cardenas, L. (2003). Investigando Marayniyoc. Revista Arqueológica Warpa 1(8), Huanta, Ayacucho.

Vaquerizo Flores, F. (2013). Forma y función de la arquitectura en el sitio de Huaqan Marca. II Ciclo de actualización profesional en Arqueología. Facultad de Ciencias Sociales, Universidad Nacional San Cristóbal de Huamanga.

Vivanco Pomacanchari, C., Pérez Calderón, I. y Rivera Pineda, F. (2000). Informe: Excavaciones de salvataje arqueológico y pagapus en los valles de Huanta y Huamanga-Ayacucho. Oficina General de la Universidad Nacional de san Cristóbal de Huamanga. 


\section{SOBRE EL AUTOR}

\section{Ismael Pérez Calderón}

Arqueólogo por la Universidad Nacional de Trujillo, Magíster en Arqueología Andina por la Universidad nacional Mayor de San Marcos. Ha participado en proyectos de investigación, conservación y puesta en valor en diferentes regiones del Perú, autor de varios artículos en revistas especializadas y libros, entre los que destaca "Huari: misteriosa ciudad de piedra", "Vilcashuaman: Paisaje, Historia y Tradición", "El Arte Rupestre en el valle de Huamanga y Monumentos Arqueológicos de Santiago de Chuco la Libertad".

Actualmente es profesor investigador, adscrito a la facultad de Ciencias Sociales de la Universidad Nacional de San Cristóbal de Huamanga, donde ha organizado distintos eventos de Ciencias Sociales a nivel regional, nacional e internacional. 